Review

\title{
The New Moon: Major Advances in Lunar Science Enabled by Compositional Remote Sensing from Recent Missions
}

\author{
Deepak Dhingra \\ Department of Earth Sciences, Indian Institute of Technology Kanpur, Kanpur, UP 208016, India; \\ deepdpes@gmail.com or ddhingra@iitk.ac.in; Tel.: +91-512-2597497 or +91-852-8024595
}

Received: 31 October 2018; Accepted: 10 December 2018; Published: 18 December 2018

\begin{abstract}
Volatile-bearing lunar surface and interior, giant magmatic-intrusion-laden near and far side, globally distributed layer of purest anorthosite (PAN) and discovery of Mg-Spinel anorthosite, a new rock type, represent just a sample of the brand new perspectives gained in lunar science in the last decade. An armada of missions sent by multiple nations and sophisticated analyses of the precious lunar samples have led to rapid evolution in the understanding of the Moon, leading to major new findings, including evidence for water in the lunar interior. Fundamental insights have been obtained about impact cratering, the crystallization of the lunar magma ocean and conditions during the origin of the Moon. The implications of this understanding go beyond the Moon and are therefore of key importance in solar system science. These new views of the Moon have challenged the previous understanding in multiple ways and are setting a new paradigm for lunar exploration in the coming decade both for science and resource exploration. Missions from India, China, Japan, South Korea, Russia and several private ventures promise continued exploration of the Moon in the coming years, which will further enrich the understanding of our closest neighbor. The Moon remains a key scientific destination, an active testbed for in-situ resource utilization (ISRU) activities, an outpost to study the universe and a future spaceport for supporting planetary missions.
\end{abstract}

Keywords: The Moon; lunar exploration; lunar volcanism; lunar crust; lunar magma ocean; mare basalt; lunar volatiles

\section{Introduction}

The Moon holds great scientific importance as a celestial body and has been a key source of knowledge in our understanding of the solar system, including our own Earth. The initial views of the impact bombardment history along with the concept of the magma ocean came from the studies of the lunar samples (e.g., [1,2]). Crater count-based age dating of the planetary surfaces across the solar system is still based on the inferred correlation between crater size frequency distribution (CSFD) and radiometric ages of the rocks at the Apollo landing sites (e.g., [3-7]). The proximity of the Moon to the Earth, along with the comparatively short-lived geological activity of the former, has enabled the extrapolation of the current lunar surface geology to the likely conditions on the Earth in the distant past. Such records (viz. isotopic, impact) of early Earth are either totally lost on the Earth or are very obscure. These records include the trends in impact bombardment rates through geological time and the record of solar activity. Interestingly, it has also been shown that fragments of the Moon may have been transported to the Earth by large impacts (e.g., [8]). Some of the records of past events on the Earth and the Moon exhibit striking correlations, further strengthening the case for a strong Earth-Moon geological relationship (e.g., [9]) in space and time. The crater-covered surface of the Moon is a very good representation of the Earth's distant past, the lost face of the Earth that holds clues to 
our planet's early evolutionary history. The most widely accepted (although still actively debated) theory of the Moon's origin via impact of a Mars-size object (commonly referred to as Theia) into early Earth implies that the Earth-Moon system is very closely related (e.g., [10-13]). Several other versions of this broad hypothesis have evolved in the recent time (e.g., [14-16]) with some of them being guided by the recent findings from missions and lunar samples.

\subsection{The First Phase of Lunar Science}

The time between the first telescopic observation of the Moon by Galileo (1609) to the Apollo and Luna landings in early 1970s (and subsequent analysis of the lunar samples) span almost three centuries of observations, hypotheses and validation of popular theories that provided numerous perspectives on the astronomical, dynamical and geological aspects of the Moon (e.g., $[17,18])$. The tidally locked nature of the Moon, its slow but continuous drift away from the Earth (indicating that it was much closer to the Earth in the past), the recognition of abundant circular features on the Moon as impact craters (after prolonged debate on them being volcanic calderas) and the large dark patches being recognized as volcanically emplaced lava were some of the major landmarks in lunar science (e.g., [19-26]).

Continued telescopic studies, as well as lunar sample and meteorite analyses, revealed new details about these original observations (Figure 1). The recognition of the rugged regions on the Moon as the mono-mineralic primary crust (e.g., [2]); the revelation of the enormous range in the titanium content of lunar mare basalts (e.g., [27-30]) along with their wide diversity in the visible and near infrared spectral reflectance (e.g., [31-33]); the discovery of mountains of olivine-bearing lithology at Copernicus crater [34]; the phenomenon of space weathering and its effects on lunar rocks, especially their spectral signatures (e.g., [35]); the large clustering in ages for mare volcanism between 3.2-3.8 billion years (e.g., [36]); incompatible element enrichment, referred to as KREEP (Potassium, Rare Earth Elements and Phosphorus), (e.g., [37]); the contrasting trends in Europium (Eu) concentration between Mare (negative) and Highlands (positive); the finding of small fragments of pure anorthite and the relatively rare occurrence of evolved granitic lithologies together sparked a revolution of sorts in trying to piece together the geological evolution of the Moon. These findings were complemented by several geophysical experiments carried on-board the Apollo missions which provided information about the near surface and deeper structure of the Moon, including layering in the lunar maria (e.g., [38]). The contributions from the Apollo and Luna missions, as well studies of the lunar meteorites, are too significant and enormous, deserving a separate publication. The above summary aims at highlighting some of the major findings that have led us into the 21st century and provides the backdrop for the current advancements in lunar science. 


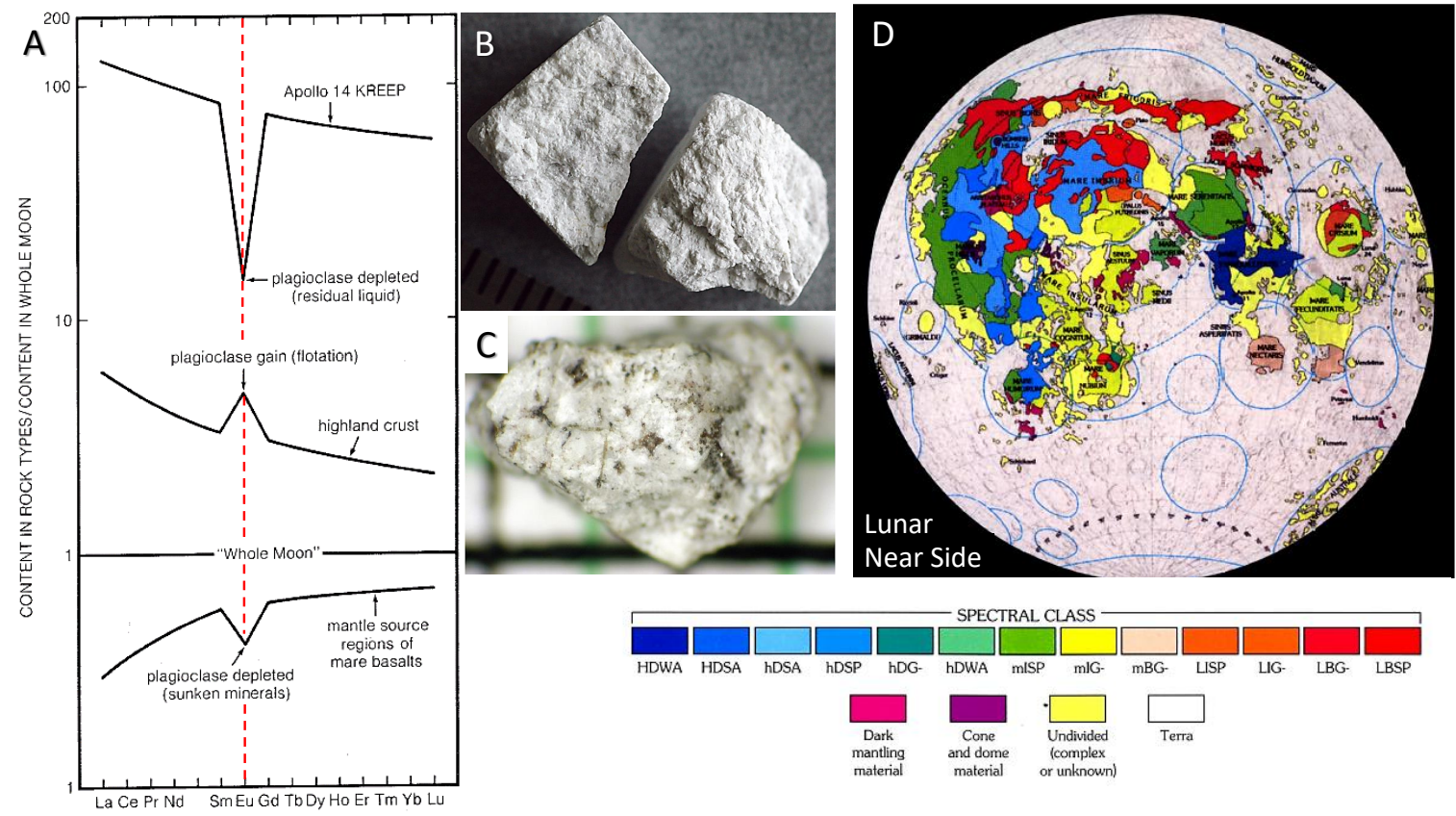

Figure 1. Sampling of important science results till Apollo era. (A) Eu anomaly in returned samples. Complementary signature of Eu between highland and mare rocks provided strong support for lunar magma ocean (Source: Modified from [39,40]). (B) Anorthosite cataclasite sample, 60025. The purity of plagioclase suggested a plagioclase-rich floatation crust as an outcome of global magma ocean differentiation (Source: [41]). (C) Lunar granite sample, 12032, 366-19 represent a restricted suite of evolved rocks produced towards late stages of the magma ocean (Source: [42]). (D) Spectral variability of basalts on the lunar near side, based on telescopic observations, provide a sampling of the mantle (Source: Modified from $[33,43,44])$.

\subsection{Post-Apollo Spike in Lunar Research}

Before the last decade, a major spike in lunar science was contributed by two small missions, Clementine (launched in 1994) and Lunar Prospector (launched in 1998) (e.g., [45,46]) and to a certain extent by the Galileo mission (launched in 1989) which had briefly observed the Moon before heading to its prime target, the Jupiter system [47]. Together, these missions provided the first global views of the Moon in elemental, mineralogical, topographical and geophysical aspects, marking a major departure from the originally lunar sample-focused, localized views of the Moon, which used to be extrapolated to the entire Moon. The telescopic observations did provide a regional perspective in some domains but were restricted to the nearside observations, leaving the entire lunar far side dependent on extrapolations. This oversimplification and its pitfalls were rapidly overcome by the global datasets from the Clementine and Lunar Prospector missions and regional views offered by the Galileo mission. One of the major highlights included the generation of global elemental maps of $\mathrm{Fe}$, $\mathrm{Ti}, \mathrm{Al}$ and $\mathrm{Mg}$ at different spatial resolutions (e.g., [48-51]) and the recognition of KREEP concentration within the Procellarum region on the lunar near side (with very limited occurrences on the far side). Together, this information formed the basis for the classification of major lunar terranes: Procellarum KREEP Terrane (PKT), Feldspathic Highland Terrane (FHT) and the South Pole Aitken Terrane (SPAT), the latter representing the largest and oldest known impact basin on the Moon (e.g., [52]). One of the most fascinating (and controversial) discoveries from the Clementine mission was the observation of hydrogen enhancement over the lunar poles, which was interpreted as potential evidence for water ice (e.g., [53]), something that was predicted theoretically many decades ago (e.g., [54,55]). The hydrogen enhancement at the poles (in the form of water ice) has very important implications as a future lunar resource and also in terms of the origin and distribution of volatiles on planetary bodies. This significant finding led to an intense debate about the occurrence of water ice (and other volatiles) in 
the polar regions and facilitated the lunar prospector mission with the specific objective of confirming the presence of water on the poles using sophisticated instrumentation including gamma-ray and neutron spectrometers (e.g., [46]). The results from Lunar Prospector, although positive, were far from being conclusive, as additional complexities were revealed in the detection strategies (e.g., [56]). Major geophysical forays were also made during this time with a global gravity and topographic map of the Moon and much improved elemental maps constrained by direct (although coarse) measurements of several elements through their gamma ray emissions (e.g., [57,58]). This global information suite provided multiple new perspectives to constrain the understanding of the lunar geological evolution (Figures 2 and 3).
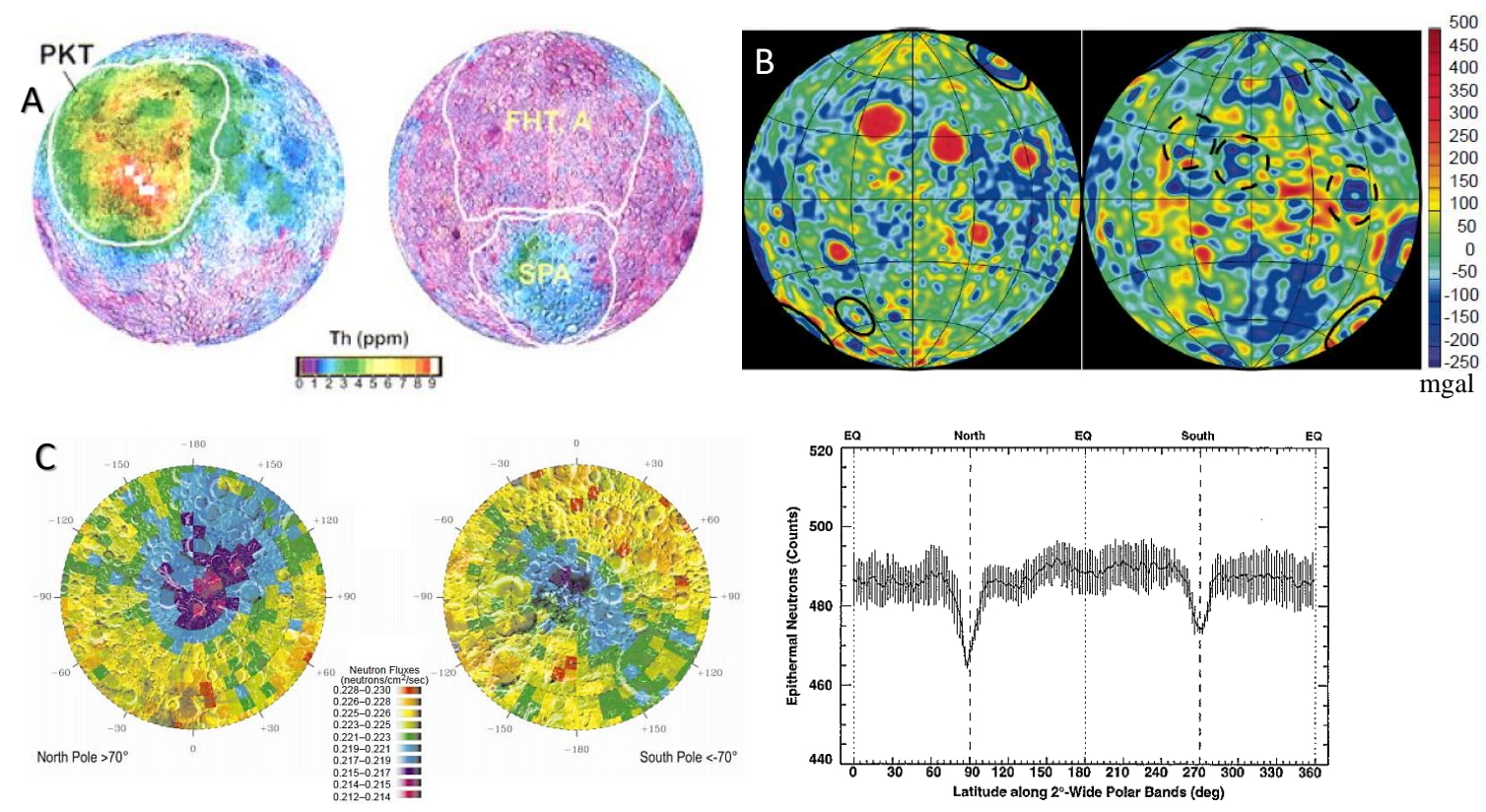

Figure 2. Scientific results from global lunar datasets. (A) Identification of major lunar terranes, their geologic context and scientific relevance (Source: [52]). (B) Gravity signatures of the near and far side of the Moon obtained from Lunar prospector mission (Source: [59]). (C) Polar maps of epithermal neutron fluxes measure by lunar prospector spacecraft, hinting at the presence of hydrogen-bearing species concentrated at the lunar poles and interpreted to be likely water-ice. The distinctive dips in epithermal neutron flux over poles highlighted the different character of neutron absorbers at the poles (Source: [56]).

Mineralogical and elemental investigations of the central peaks of impact craters were used to constrain the compositional structure of the lunar crust (e.g., [60,61]), and improved age dating of different basalt units led to much better understanding of the volcanic evolution and recognition of the $\sim 1$ billion year old mare volcanism episode which extended the geologically active nature of the Moon to much younger time scales than previously thought (e.g., [62,63]). Additional evidence for an active Moon (in the form of outgassing) was presented in the form of the morphologically and spectrally fresh-looking Ina structure at Mare Tranquillitatis [64]. The new analyses also strengthened the case for no observable trend between the age of mare basalts and their titanium concentration (e.g., [65]). Several new science questions were also raised by the new datasets, including the origin of thorium anomalies on the lunar far side, namely at the Compton-Belkovich region, Dewar and within the South-Pole Aitken basin (exposed at two impact craters). It has been unclear if these locations were related to the KREEP layer on the lunar nearside. In addition, there are perennial questions in lunar science that remain poorly answered, including the origin of the crustal thickness differences between the near and the far side, the origin of the lunar swirls, the origin of the Procellarum region, the character of the late heavy bombardment and the nature of the lunar core. Some of these questions 
are directly linked to the planetary evolution process, while others have broad implications for the solar system. Needless to say, more observations and new perspectives of the Moon are still required to answer some of these scientific challenges.
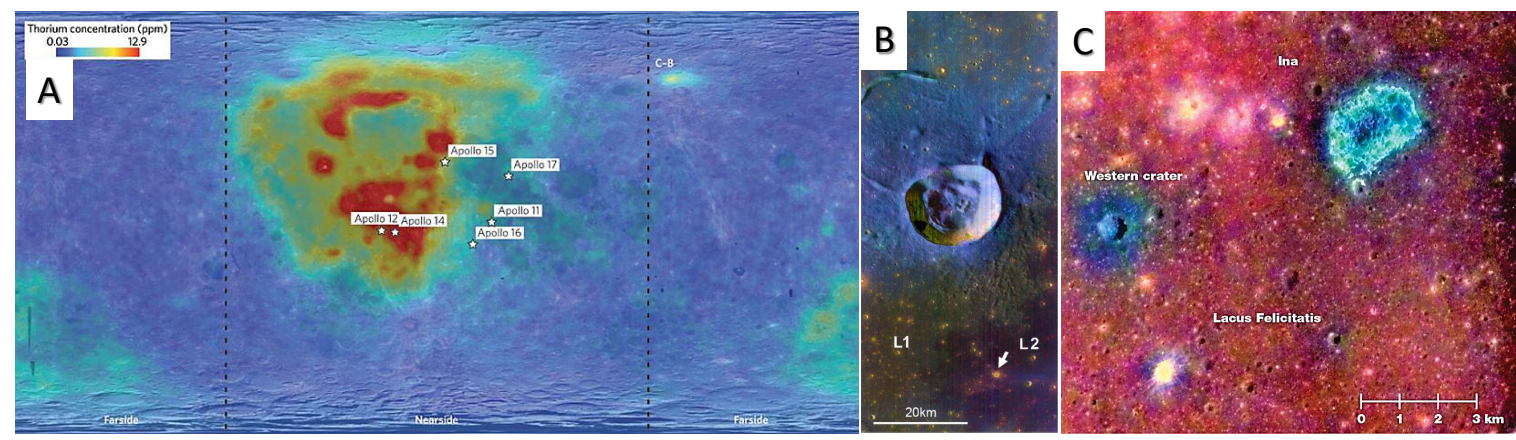

Figure 3. Compositional and age variability in lunar basalts. (A) Large variations in Thorium concentrations (a proxy for Potassium, Rare Earth Elements and Phosphorus (KREEP)) between near and far side, as observed by lunar prospector observations (Source: [66], NASA). (B) Very young basalts ( 1 b.y.) around Lichtenberg crater (Source: [67]). (C) Geologic (and spectral) freshness of Ina D structure was suggested to be an evidence for recent outgassing from the lunar interior (Source: [64]).

\section{Renaissance in Lunar Science in the Last Decade (2008-2018)}

The most recent phase of advancement in lunar science has not only been in the direction of addressing some of the outstanding questions but, also in terms of critically evaluating the lunar resource potential for future colonization. Efforts have been specifically targeted to obtain a wide diversity of high quality datasets to enable surface exploration of the Moon by landers, rovers and humans in the near future. Exploration of the Moon in the last decade has been undertaken by multiple nations, including China, India, Japan, United States and several countries from the European Union (Figure 4). High quality data from modern sensors onboard orbiters and landed missions have significantly advanced the understanding of our closest neighbor. A major period of renaissance in lunar science is currently in progress. This giant leap in our knowledge about the Moon (with important implications for the solar system in many cases) is multi-faceted. On one hand, either new scientific domains have opened up (viz. lunar volatiles) or poorly constrained aspects have been greatly strengthened (viz. lunar exosphere and thermal environment). On the other hand, fundamental understanding of the Moon's origin and subsequent evolution has been thoroughly challenged, necessitating a detailed revamp of theories and models. The re-shaping of lunar science, based on recent remote sensing datasets, has just started and will likely drive the research for several years (if not decades) ahead. The scientific advances made in the last decade have varied implications on variety of spatial scales (viz. global-scale, regional scale or site-specific). The results are accordingly presented providing the relevant context. In addition, though the major focus of this publication is on the results obtained from remote sensing data, we have also selectively included findings based on samples, experiments and models, guided by their strong complementary nature. Global scale processes and products are the major drivers of planetary evolution and also the ones which are generally best studied via remote sensing. With global remote sensing data available not only at high spatial and spectral resolution but also increasingly high temporal resolution, interesting new insights are emerging, some of them for the very first time. Volatiles on the lunar surface represent one of those key findings that are rapidly changing our views of the Moon and its exploration potential. 


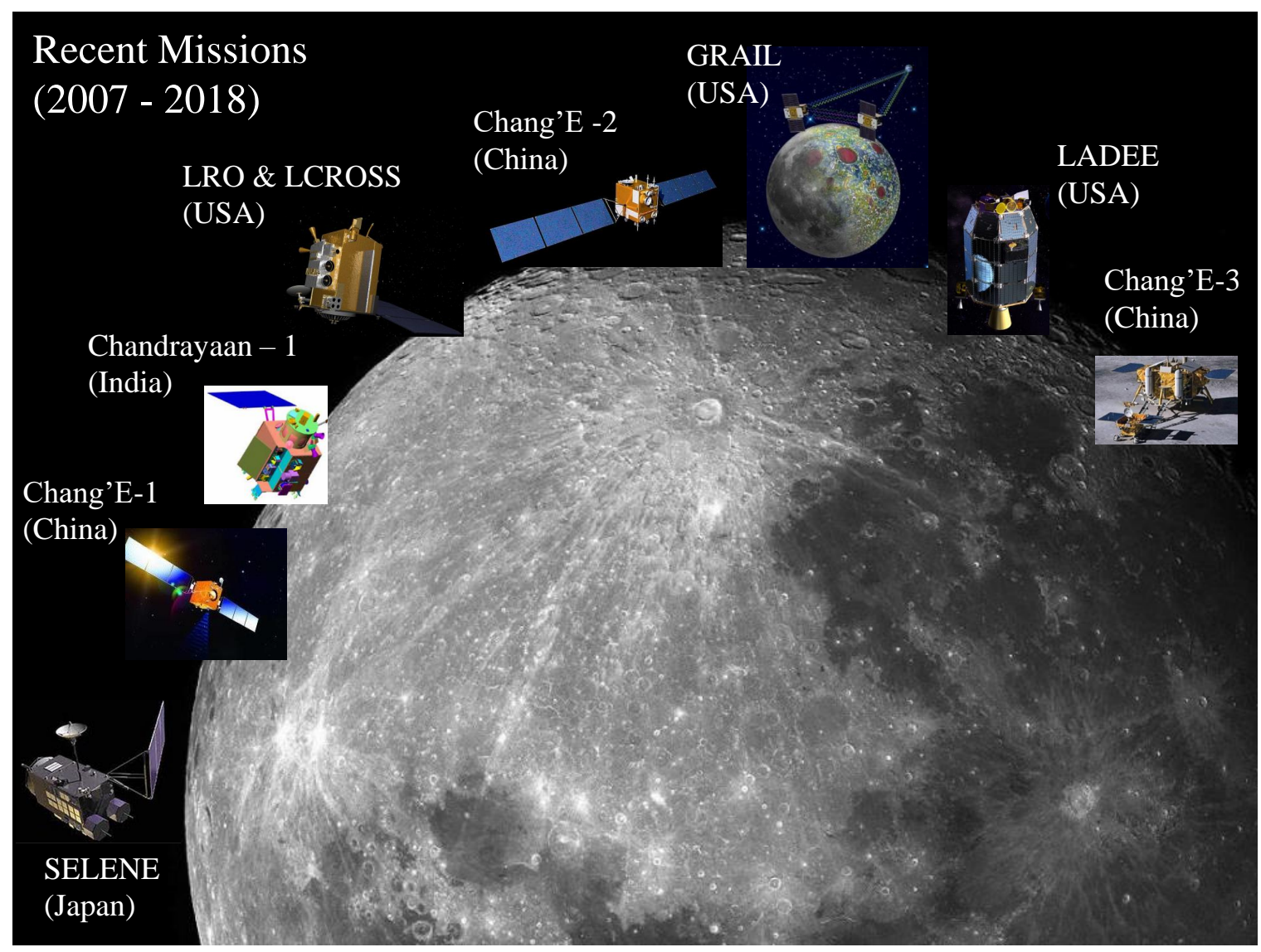

Figure 4. Missions to the Moon in the last decade. Credits for individual images: JAXA, CNSA, ISRO and NASA.

\subsection{Volatiles}

Volatile species of diverse nature have now been discovered on the Moon. Lunar volatiles could perhaps be regarded as one of the most important findings in planetary science in the last decade and certainly a key milestone in lunar research. The recent data have revealed volatiles in different physical forms and at different spatial scales, which is much beyond what had been predicted in the past or inferred from previous missions. There are three distinct types of volatiles currently recognized on the Moon (Figure 5).

\subsubsection{Volatiles Associated with the Lunar Interior}

These represent the first major discovery based on the re-analysis of returned lunar samples (starting with volcanic glasses), enabled by the advancements in the analytical abilities (e.g., [68]). The investigations reported significant concentrations of various volatile species, including $\mathrm{H}_{2} \mathrm{O}, \mathrm{F}, \mathrm{Cl}$ and inferred an in-situ origin of the volatiles based on the degassing trend systematics from core to the rim of the analyzed lunar glass-beads. Follow-up investigations including the study of fluid inclusions locked inside olivine crystals in the glass beads have increasingly strengthened the argument for an in-situ source of volatiles, including water, on the Moon, although the resolution of certain debates would require additional analyses (e.g., [69-72]). This includes the suitability of the mineral apatite in determining the primordial volatile abundances in the melt. Recent work has argued that although apatite is found in both basalts and highland rocks which enables the determination of associated volatile contents in space and time, the volatile contents of apatites cannot be directly interpreted in terms of melt volatile concentration, unless equilibrium crystallization persisted for the entire duration (e.g., [73]). There are several important implications of these findings. With the detection of liquid water in lunar samples, the conventional modeling involving anhydrous crystallization of magmas on 
the Moon needs to be re-considered. The detection of volatiles has also raised important questions about the widely accepted giant impact hypothesis for the origin of the Moon. Together with isotopic studies, which have found remarkable similarities between Earth and the Moon, the in-situ volatile discovery has led to a substantial re-thinking about the giant impact scenario, including the exchange dynamics of the superheated disc of debris and the young Earth (e.g., [74]). Some answers to this puzzle have been attempted, but it remains an active area of research (e.g., [14,15,75]). Interestingly, evidence for $\mathrm{OH} / \mathrm{H}_{2} \mathrm{O}$ of magmatic origin has also been presented from remote sensing data for multiple locations on the Moon, including the central peaks of the craters Bullialdus and Theophilus, the Compton-Belkovich Volcanic Complex (CBVC) and multiple pyroclastic deposits (e.g., [76-80]). Caution should however be exercised in the detailed characterization of the hydration signatures based on the available data, as there is only partial coverage of the hydration absorption band. It is also important to note that the key observations represent the last few bands in the spectral coverage of the instrument where the detector spectral response may not be as reliable. Upcoming missions (discussed in Section 3) would hopefully enable a much more detailed investigation. Another key aspect that would benefit from future lunar exploration, through orbiters, landers and sample return, is an understanding of the volatile reservoir of the Moon. It is important to know whether the lunar volatile reservoir is homogeneous and pervasive or heterogeneous with volatile-rich pockets in the lunar interior. Each scenario will have its own implications for both the origin and the evolution of the Moon.

\subsubsection{Volatiles Associated with Topmost Surface}

The second major discovery of volatiles on the Moon has been in the form of a globally distributed monolayer of $\mathrm{OH} / \mathrm{H}_{2} \mathrm{O}$, based on the near-infrared spectral signatures. One of the most remarkable aspects of this discovery is the detection of volatiles in space and time by three different instruments on three different spacecrafts: Visible and Infrared Spectrometer (VIMS) onboard the Cassini mission to Saturn system, Moon Mineralogy Mapper $\left(\mathrm{M}^{3}\right)$ onboard Chandrayaan-1 mission to the Moon and High Resolution Instrument-Infrared Spectrometer (HRI-IR) onboard Deep Impact (EPOXI) mission to Comet 103P/Hartley 2 (e.g., [81-83]). The result was also independently confirmed by the in-situ measurements of the lunar exosphere and near surface through Chandra's Altitudinal Composition Explorer (CHACE) mass spectrometer onboard the Chandrayaan-1 mission (e.g., [84]). The complementary nature of the results provided by these observations separated in space and time provided an unambiguous detection of $\mathrm{OH} / \mathrm{H}_{2} \mathrm{O}$ on the Moon. Numerous aspects of this mono-layer have been investigated by remote sensing, experiments and modeling. These include the origin of the $\mathrm{OH} / \mathrm{H}_{2} \mathrm{O}$ and their dependence on various physical parameters, such as surface temperature, lithology, time of the day and latitude (e.g., [85-87]). An origin involving solar wind interaction with the lunar surface seems likely, although debates are still underway about the dominant controls and their influences on the occurrence and distribution of this lunar volatile species (e.g., [88]).

\subsubsection{Volatiles Associated with the Lunar Poles}

The lunar polar volatiles, unlike lunar indigenous water or surficial monolayer, were predicted to exist in the permanently shadowed polar regions for a long time (e.g., [54,55]) and the detection of polar hydrogen bearing deposits was reported by the Clementine and Lunar prospector missions (e.g., [53,56]). Important resource implications have been a driving force in knowing the exact nature of these volatiles on the lunar poles. Intensive efforts in observations, experiments and modeling have been made to understand the nature of these volatiles. The first set of encouraging results in the last decade came from the Miniature Synthetic Aperture Radar (Mini-SAR) instrument onboard Chandrayaan-1, with the detection of radar backscattered signals from putative water-ice deposits inside permanently shadowed craters (e.g., [89]). Subsequently, volatiles were detected by the Lunar Crater Observation and Sensing Satellite (LCROSS) mission, which involved an impact into Cabeus crater (on the lunar south-pole) and observations of the ejecta plume by a trailing spacecraft (e.g., $[90,91])$. Several instruments onboard the 
currently orbiting Lunar Reconnaissance Orbiter (LRO) mission have contributed additional insights into the polar volatiles, including the Lunar Exploration Neutron Detector (LEND), Miniature Radio Frequency (Mini-RF), Diviner and Lunar Orbiter Laser Altimeter (LOLA). The LEND instrument predicted the highest abundance of polar hydrogen on the south polar Cabeus crater, leading to its selection as the LCROSS impact site (e.g., [92]). Extensive coverage of the poles by the Mini-RF instrument enabled the identification of craters with enhanced circular polarization ratio (CPR) only in crater interiors instead of interior and exterior, the latter being a clear indication of surface roughness induced backscattered signals. The former category of craters were thus interpreted to be water-ice bearing (e.g., [93]). The Diviner instrument has provided reliable temperature estimates enabling the identification of the coldest regions within the lunar poles, which would be prime candidates for volatile repositories (e.g., [94]). Enhancement in the brightness of the Shackleton crater at $1064 \mathrm{~nm}$ was reported by the LOLA team and suggested to be either due to less space weathered material or a possible signature of ice mixed with regolith (e.g., [95]). Suggestions of the presence of water frost have also been made (e.g., [96,97]). Exposed water-ice signatures from the lunar poles based on $\mathrm{M}^{3}$ data is the latest addition to the steadily accumulating evidence for volatile (notably water-ice) inventory on the poles (e.g., [98,99]). The far-reaching implications of polar volatiles on future lunar colonization are driving the scientific and technological efforts in this regard. It includes the scheduled southern high latitude region landing by the Chandrayaan-2 mission in early 2019 (e.g., [100]).

In the true spirit of the Moon being a cornerstone for solar system science, the discovery of lunar volatiles, especially the mono-layer $\left(\mathrm{OH} / \mathrm{H}_{2} \mathrm{O}\right)$, has sparked successful discoveries of volatiles on other airless bodies (e.g., [101,102]). It's interesting to note that several of the detections have been based on the re-analysis of pre-existing datasets. This includes the lunar $\mathrm{OH} / \mathrm{H}_{2} \mathrm{O}$ signature in the Cassini mission observations of the Moon made in 1999 (e.g., [81]). An altogether different perspective gained from the distribution of polar volatiles, that of the true polar wander of the Moon, has also been revealed by the analysis of old data from the Lunar Prospector mission (e.g., [103]). Another fresh perspective has come from the estimation of outgassing during the emplacement phase of mare basalts. It has now been suggested that not only a transient lunar atmosphere $(1.5 \times$ Martian atmospheric pressure) could have survived for $\sim 70$ million years, a tiny amount of this volatile inventory could also have ended up in the lunar poles (e.g., [104]). This possibility suggests that the volatiles at the poles might be sourced not only from comets and solar wind but also from the lunar interior. Future missions may or may not be able to differentiate between the volatiles obtained from different sources and processes. The nature of volatile enrichment process (viz. continuous, episodic) by different sources, the relative timing of volatile contribution by various sources (viz. early phase, late phase), various mixing processes including regolith mixing time scale, as well as loss mechanisms of each of the volatile species, would directly affect the ability to tag volatile species to a particular source or process. 

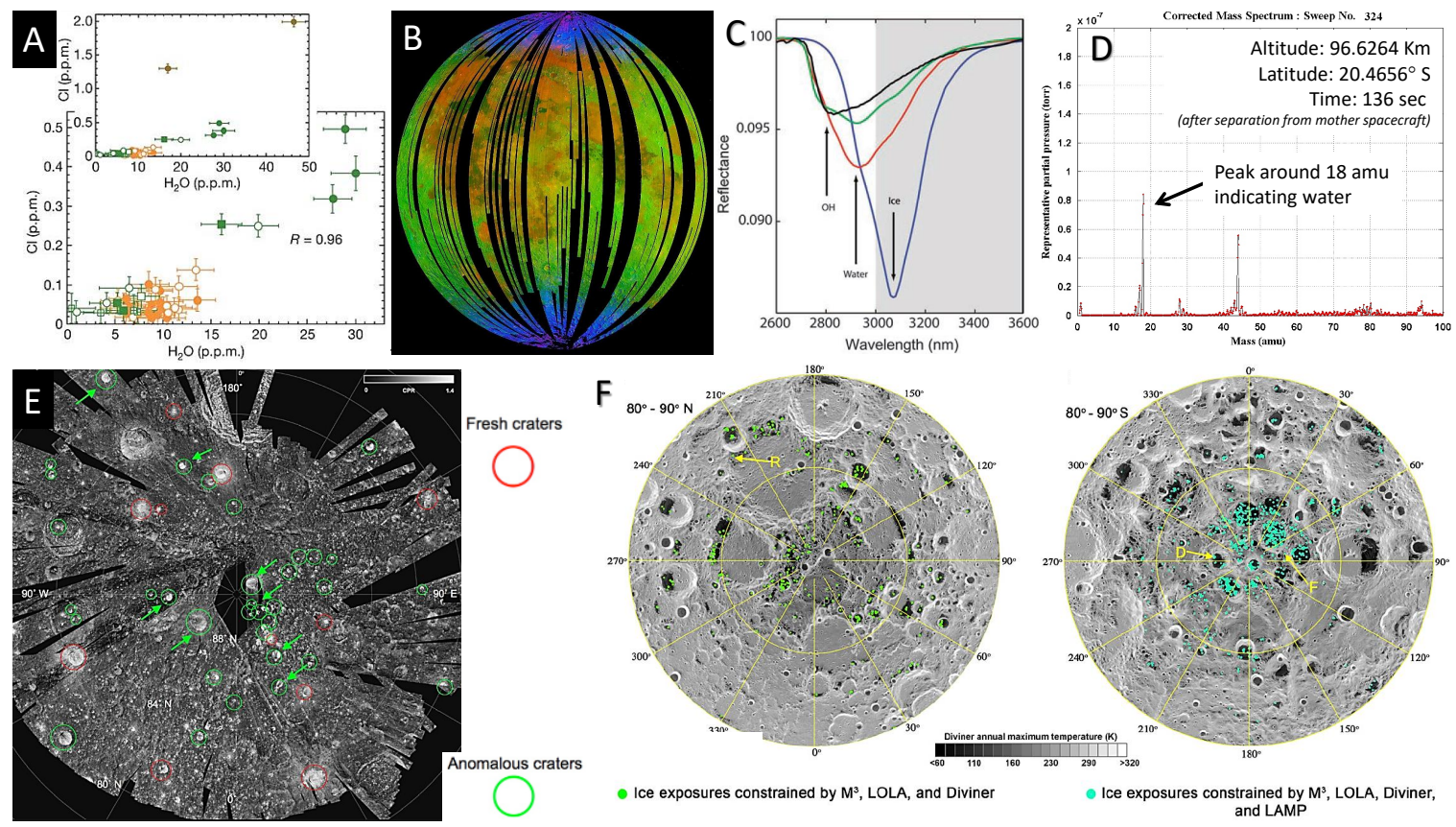

Figure 5. Discovery of three different flavors of volatiles on the Moon. (A) Water (and other volatiles) in the lunar interior, measured directly in lunar samples (Source: [68]). (B) $\mathrm{OH} / \mathrm{H}_{2} \mathrm{O}$ on the lunar surface measured by remote sensing (Source: [NASA]). (C) Near infrared signatures of $\mathrm{OH}, \mathrm{H}_{2} \mathrm{O}$ and Ice (Source: [82]). (D) In-situ detection of surficial water on the Moon. The distinct peak at mass no. 18 has been interpreted to be signature of water (Source: Modified from [84]). Water-ice signatures on the lunar poles detected at (E) radar wavelengths (Source: Modified from [89]) and (F) integrated datasets including near-infrared, thermal wavelengths (Source: [99]).

\subsection{Lunar Magma Ocean Concept}

The Moon's evolution from a globally molten ocean of magma (of uncertain vertical extent) has been one of the core concepts in planetary science, borne out directly from the samples returned by the Apollo missions (e.g., [2]). It has led to the conceiving of magma oceans on other large planetary bodies, including our Earth (e.g., [105,106]). However, it has also been a real challenge for over four decades to satisfactorily understand the workings of such a magma ocean, especially the formation of plagioclase-rich crust and the distribution of the KREEP layer. Intertwined questions about the vertical extent, duration and cooling history of the magma ocean are central to the debate and have also led to the idea of serial magmatism as an alternative hypothesis or an additional component to the originally proposed plagioclase-rich floatation crust (e.g., [107,108]).

\subsubsection{Global Occurrence of Pure Plagioclase Layer}

Globally distributed exposures of purest anorthosite ( 98 vol \% anorthite; PAN) on the Moon have been reported based on remote sensing data acquired in the last decade (e.g., [109,110]). Three independent instruments onboard two lunar missions, namely the Multi-band imager (MI) and Spectral profiler (SP) on the Japanese Kaguya mission and NASA M $^{3}$ on the Indian Chandrayaan-1 mission, have characterized the diagnostic 1.25 micron crystalline absorption band of plagioclase, enabling its confident identification and determination of purity (Figure 6). The absorption band is caused by to the presence of a small amount of $\mathrm{Fe}^{2+}$ in the crystal structure of plagioclase (e.g., [111-113]). It has now been strongly suggested that a global crustal layer of pure anorthosite exists on the Moon. At the same time, the estimated purity of these crystalline plagioclase exposures ( $98 \mathrm{vol} \%)$ has been debated, as it seems petrologically very difficult to have such an efficient crystallization scenario where even the residual fluid, usually locked up in the voids, can be removed. Recent modeling efforts have proposed a possible mechanism to generate PAN rocks in a magma ocean crystallization 
scenario (e.g., [114]). Additionally, more and more lunar samples are being found in Apollo collections and meteorites with plagioclase purity consistent with remote sensing estimates (e.g., [115]). New experimental measurements of the late lunar magma ocean liquid suggests a stratified crust with mafic-rich older crustal component and mafic-poor younger crustal component (e.g., [116]). A key constraint that would help petrologists in understanding the formation of the PAN layer from magma ocean crystallization is its thickness and the depth of emplacement in the crust. Although estimates for both the parameters have been suggested ( $\sim 50 \mathrm{~km}$ thick layer located at a depth of $\sim 10 \mathrm{~km})$, it is unclear whether it should be the same all over the Moon, given the crustal thickness differences on the near and the far sides (e.g., [117]). This aspect is also important in view of the suggested model of asymmetric crustal growth with respect to the near and farside crust (e.g., [118]). The model suggests the far side highlands to be more primitive (higher Mg\#) than the near side highlands (lower Mg\#). Detailed mapping of pure plagioclase exposures at regional scale at Orientale basin (diameter: $930 \mathrm{~km}$ ), has highlighted the occurrence of a very coherent PAN layer associated with the Inner Rook ring (IRR) providing a strong constraint on the depth of this layer at least at Orientale [119].

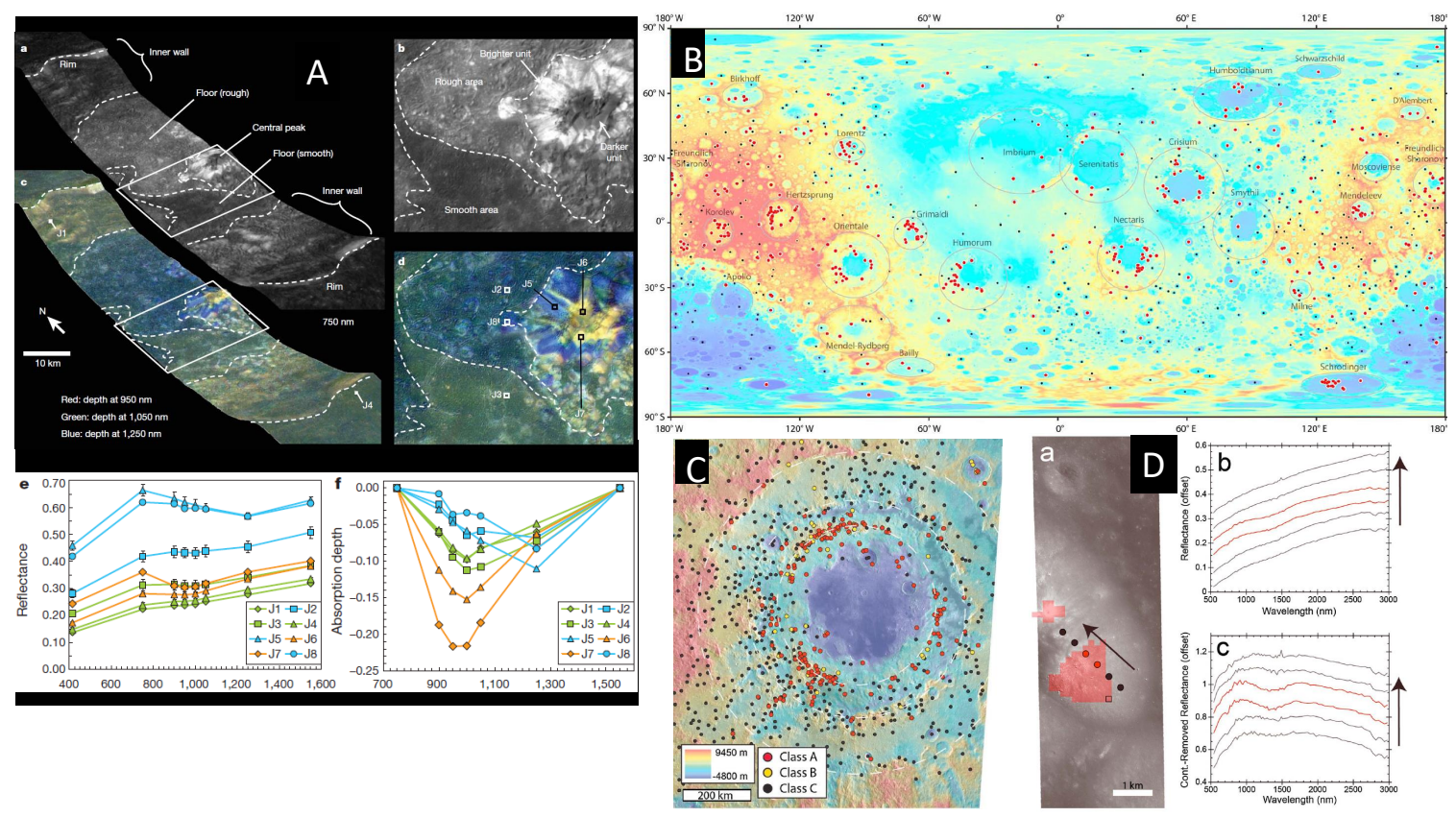

Figure 6. Distribution and geologic setting of purest anorthosite (PAN) exposures. (A) Crystalline plagioclase signatures observed at Jackson crater central peaks based on near infrared datasets (Source: [109]). (B) Global distribution of crystalline plagioclase based on a combination of near infrared and thermal infrared datasets. The red dots represent positive identifications. The black dots indicate locations sampled but no plagioclase detection (Source: [110]). (C) Geologic context of purest plagioclase exposures at Orientale basin. Preferential occurrence along the Inner Rook Ring (IRR) is exhibited providing strong depth constraints of purest plagioclase layer (Source: [119]). (D) Relationship of purest plagioclase exposures with featureless spectra (Source: [119]).

\subsubsection{Global Occurrence of Featureless Spectra-Origin and Associations}

The occurrence of crystalline plagioclase on the Moon is also intimately associated with extensive exposures of featureless spectra, prompting speculations about the origin of these exposures and whether they are also part of the plagioclase-rich layer. Conventionally, featureless spectra have been considered as representative of shocked plagioclase lithology, since plagioclase loses its crystal structure (the cause of 1.25 micron absorption feature) relatively easily during shock events (viz. meteoritic impacts) (e.g., [120,121]). However, recent studies of shocked plagioclase using remote sensing data as well as laboratory measurements of lunar samples suggest multiple possibilities, including featureless spectra being space weathered PAN mineralogy, shocked plagioclase (with the caveat that there should 
be a glass band at 1 micron), iron-free plagioclase $(<0.1 \% \mathrm{FeO})$ or finely fractured plagioclase with abundant internal scattering that does not generate strong enough absorption signal to be detected (e.g., [122,123]). The occurrence of crystalline plagioclase exposures within featureless spectra at basin rings and crater central peaks has also highlighted a potential knowledge gap in our understanding of the peak shock-pressures produced during impact events and their distribution in the target. Unambiguous detection of crystalline plagioclase in the central peaks and basin rings suggest that they were not subjected to high enough shock pressures to erase their crystalline structure.

\subsubsection{Large Spread in Crystallization Ages of Primordial Crust-Conundrum and New Views}

Vast spread in the radiometric ages of the anorthositic rocks (ferroan anorthosites) has had been another key challenge for the magma ocean hypothesis and taken at face value, requires a long time for magma ocean solidification, necessitating mechanisms for sustaining the magma ocean or raising the possibility of primary crust formation through other mechanisms (e.g., [124,125]). Beyond radiogenic heating from short-lived radioactive isotopes, tidal heating from the Earth, insulation by floatation crust and energy from impacts have been suggested although the latter could also blast away portions of the insulating layer, expediting magma ocean solidification (e.g., [126,127]). The large spread in the radiometric ages of ferroan anorthosites could also possibly be explained by the origin of at least some of them through recycling and secondary crystallization. In such a scenario, there would be an anorthosite population which would not have a primordial origin (e.g., [128]).

\subsubsection{KREEP and Proxies-Insights into Primordial Crust Formation}

The residual soup of incompatible elements left towards the end of magma ocean crystallization, KREEP, has been another enigma of sorts, at least in the context of its spatial distribution on the Moon. The occurrence of KREEP was initially documented by returned lunar samples but was subsequently mapped remotely by gamma ray spectroscopy through the detection of radioactive element thorium and some rare earth elements (e.g., $[129,130])$. Unlike the global distribution of lunar anorthosites, KREEP is mainly concentrated on the lunar near side, around the Procellarum region. The lunar far side only has sporadic occurrences of high thorium concentrations, with major exposures at Compton-Belkovich region, Dewar anomaly and two craters within the South-Pole Aitken (SPA) basin (e.g., [130]). It is an open question whether the far side thorium occurrences are related to the near side and what their vastly different spatial distribution means. Technological advancements in the last decade have enabled global mapping of additional incompatible radioactive elements (Figure 7): potassium (K) by Chinese Chang'E-1, Chang'E-2 mission and Uranium (U) by the Japanese Kaguya mission, for the first time. (e.g., [131,132]). Apart from the broad positive correlations between all the three radioactive elements for the Procellarum region, SPA and Compton-Belkovich region, statistically significant differences in U/Th ratio have been reported between western and eastern farside regions, possibly indicative of heterogeneous formation of the farside crust [131]. This may also be important in the context of the observed nearside-farside crustal dichotomy. Apart from new elemental measurements, advancements in the analytical techniques are enabling much higher spatial resolution elemental maps from earlier missions and providing new scientific insights (e.g., [133]). Pixon-based image reconstruction of lunar prospector thorium maps have led to the recognition of much wider thorium spread around the Compton-Belkovich region than defined by the spatial extent of albedo anomaly in that region. Accordingly, origin of Compton-Belkovich by explosive silicic volcanism has been proposed, consistent with the results from independent studies (e.g., [134,135]). 

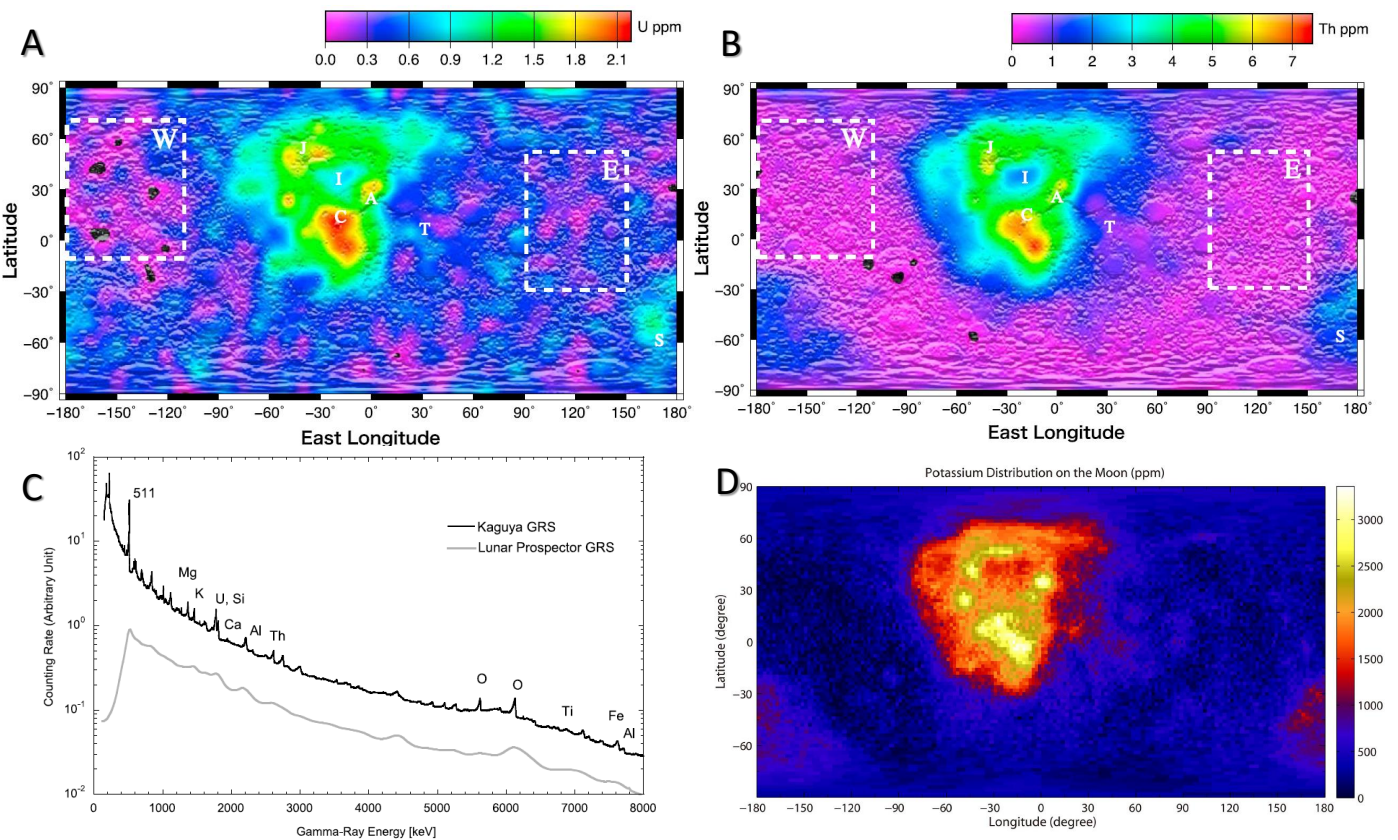

Figure 7. New Measurements of incompatible elements with modern sensors. (A) Uranium distribution exhibits spatial differences within farside highlands (Source: [131]). (B) Spatial distribution of thorium (Source: [131]). (C) Improvement in spectral resolution between Kaguya and Lunar Prospector Gamma ray spectrometers (Source: [131]). (D) Spatial distribution of potassium correlates well with the thorium distribution (Source: [132]).

\subsection{Lunar Secondary Magmatism}

Magmatic activity on the Moon has primarily been recognized in its extrusive form as mare basalts, pyroclastic deposits and silicic volcanism, each with their distinctive spatial distribution characteristics. The intrusive form of magmatism, although suggested in the past, had not been probed in great detail (with a few exceptions) till recently. Remote compositional, morphological and geophysical studies from recent datasets have now revealed several interesting new insights.

\subsubsection{Extrusive Magmatism}

Major new scientific advances in the domain of extrusive magmatism (Figure 8) include the hydrated nature of both pyroclastic deposits and silicic volcanism in the Compton-Belkovich region (e.g., $[77,80])$. It should, however, be noted that not all pyroclastic deposits or silicic volcanic constructs exhibit hydration signature, pointing to possibly either heterogeneous reservoirs inside the Moon or their different evolutionary state during various eruption events.

\subsubsection{Evolved Lithologies-Identification and Characterization}

Direct evidence for the highly silicic nature of numerous non-mare volcanic constructs has been an important finding based on the observations from Diviner radiometer onboard the LRO spacecraft (e.g., $[136,137])$. Previously referred to as lunar red spots (due to strong absorption in UV compared to reflectance at longer wavelengths), hypothesized to be silicic in nature based on high albedo and typical morphology (e.g., steep slopes), Diviner results indicate that some of the red spots are silicic (e.g., Hansteen Alpha, Mairan domes, the Lassell Massif region and the Gruithuisen Domes) while others are not (e.g., Helmet Feature, Darney Chi, Darney Tau, Montes Riphaeus, and Mons La Hire) (e.g., [138-141]). The new observations have divided the red spots into two broad classes. Further investigations of the differences between the two classes would hopefully provide additional insights into this relatively restricted flavor of extrusive magmatism on the Moon. The Compton-Belkovich region has long been recognized as an isolated thorium anomaly on the lunar far side, hinting at 
the presence of an evolved lithology at this location (e.g., [129]). However, based on the analyses from multi-mission and multi-instrument datasets, including imaging, spectral and radar data, it is now additionally recognized as the Compton-Belkovich volcanic complex (CBVC), comprised of a series of silicic domes and an extensive area of pyroclastic deposits, indicating its explosive mode of emplacement (e.g., [135,142]). Lassell massif on the near side has also been suggested to be a silicic volcano based on similar lines of evidence (e.g., [143]). Interestingly, it also shows some evidence of recent resurfacing $(\sim 60 \mathrm{Ma})$, which needs to be further explored.

\subsubsection{Young Volcanism on the Moon—New Evidences and Debates}

The most recent volcanic activity on the Moon had until recently been tied to $\sim 1$ billion years, based on the studies of basaltic exposures overlying Lichtenberg crater ejecta (e.g., [62]). However, this time-scale might need significant revision based on the high spatial resolution study of 70 small, morphologically fresh, topographic anomalies collectively referred to as irregular mare patches (IMPs). Crater count ages younger than $100 \mathrm{Ma}$ for these features have been suggested which, if true, would advance the lunar volcanic activity by an order of magnitude (e.g., [144]). Alternative interpretations (other than young age) have been offered for at least some of these features, which have been known since the Apollo era. The Ina structure is the most well-known and was recently suggested to be undergoing active resurfacing by escaping gases from the lunar interior, giving morphological freshness to this structure (and therefore younger age) (e.g., [64,138,145,146]). It has alternatively been explained as a product of inflated lava flows (e.g., [147]). IMPs have also been proposed to be the weathering product of a magmatic foam formed during the late stage of dike emplacement, a couple of billion years ago (e.g., $[148,149])$. The unusual character of the substrate has been suggested to be the cause of the observed morphology with very few superposed craters, resulting in very young ages. Thermophysical properties of the selected IMPs provide examples of both high and low-thermal inertia than typical regolith, with the latter suggested to be the product of pyroclastic eruptions or explosive outgassing (e.g., [150]). The low thermal inertia (compared to the surrounding regolith) is consistent with the predictions from [149]. High resolution morphological and mineralogical observations of Lowell crater have been presented to address the nature of some of the identified flows being simply impact melt deposits vs expression of young volcanic activity (e.g., [151-153]). The absolute model age of Lowell crater has been determined to be $\sim 374$ million years (e.g., [154]). Similar perspectives for other locations have been presented recently, reviving discussions from the distant past (e.g., [24,155]). Major new strides in the studies of impact melt deposits including their morphology, texture and mineralogy, for craters all over the Moon, have provided detailed perspectives to settle at least some of the reported ambiguities (see Sections 2.4.2 and 2.4.3). However, the ongoing debate on the possibility of very young volcanism on the Moon (or the lack of it) would benefit from additional studies from recent and future datasets. Returned samples or in-situ analysis of rocks from selected locations would be key in resolving the complexity associated with the age of the various studied features.

\subsubsection{Basalt Composition and Ages-New Updates}

The compositional character of volcanic deposits (along with their age information) is a key tracer for understanding the magmatic evolution of the Moon in terms of mantle melting events and the interaction of molten material with other lithological components before emplacement on the surface. An integrated view from high quality elemental and mineralogical composition, enabled by recent missions, has provided several new perspectives on the lunar magmatic evolution, while also refining and validating the results from the past datasets. A new variety of basalt has been reported from the Imbrium region, analyzed by ChangE'-3 Yutu rover instruments, and suggested to have been sourced from a hybridized mixture of ilmenite-rich cumulates and evolved mantle melt (e.g., [156,157]). The results from the in-situ analysis of this basalt variety provide a new ground truth location for remote sensing observations after more than four decades and it is therefore a key addition. Global abundance maps of key elements (including iron and titanium) and minerals have been produced by 
numerous techniques, including spectral reflectance and gamma-ray spectroscopy providing more reliable estimates than previously available (e.g., [158-161]). Abundant olivine-bearing character of the late stage high titanium basalts on the western near side has been validated by high spectral resolution observations, and their origin from evolved residual melt has been suggested (e.g., [67]). Detailed studies of mare basalts at Orientale basin have led to the identification of previously undetected basaltic occurrences and the recording of volcanic activity spanning the entire range of volcanism documented for the Moon (e.g., [162]). Mare basalts at Moscoviense basin exhibit diversity in their titanium concentration and ages (e.g., $[163,164]$ ). Recent analysis of the basalt mineralogy and elemental concentrations, using high spatial and spectral resolution data and new algorithms, have sub-divided the existing basalt unit classification and identified a distinctive unit in the north-eastern part of the basin (e.g., [165]). Compositional studies of basalts at Serenitatis basin provide contrasting perspectives from elemental and mineralogical analyses. Basaltic units classified based on the titanium concentration exhibit a relatively higher degree of variability (in $\mathrm{FeO}$ and $\mathrm{TiO}_{2}$ contents) in older eruptions (e.g., [166]). In contrast, basaltic units classified based on spectral differences report uniformity in pyroxene composition across units and suggest a possibly stable source which did not undergo significant fractionation (e.g., [167]). Integrated studies of basalts at Tsiolkovskiy crater have revealed a complex emplacement pattern of basaltic units with distinct differences in spectral character and titanium content (e.g., [168]). Post-emplacement modifications in the geologic setting of basalts at Tsiolkovskiy appears likely. Young lunar basalts $(\sim 1.2-2.8$ billion year) on the near and the far side have been found to not exhibit any distinctive mineralogical character, except perhaps higher FeO at Orientale and western nearside region (e.g., [169]). Recent experimental and modeling work has identified pink spinel anorthosite (PSA) as a new member of the Mg-suite of rocks and suggested it to be a proxy for identifying locations of Mg-suite magmatism on the Moon (e.g., [170]). Globally distributed PSA locations have been used to predict potential sites of Mg-Suite volcanism, a flavor that has not been commonly observed despite its lower viscosity than mare basalts (which have been extensively extruded on the lunar surface) (e.g., [171]). An interesting corollary to the PSA - Mg-Suite linkage is the suggestion that KREEP may be a non-essential component in the petrogenesis of the Mg-suite of rocks.
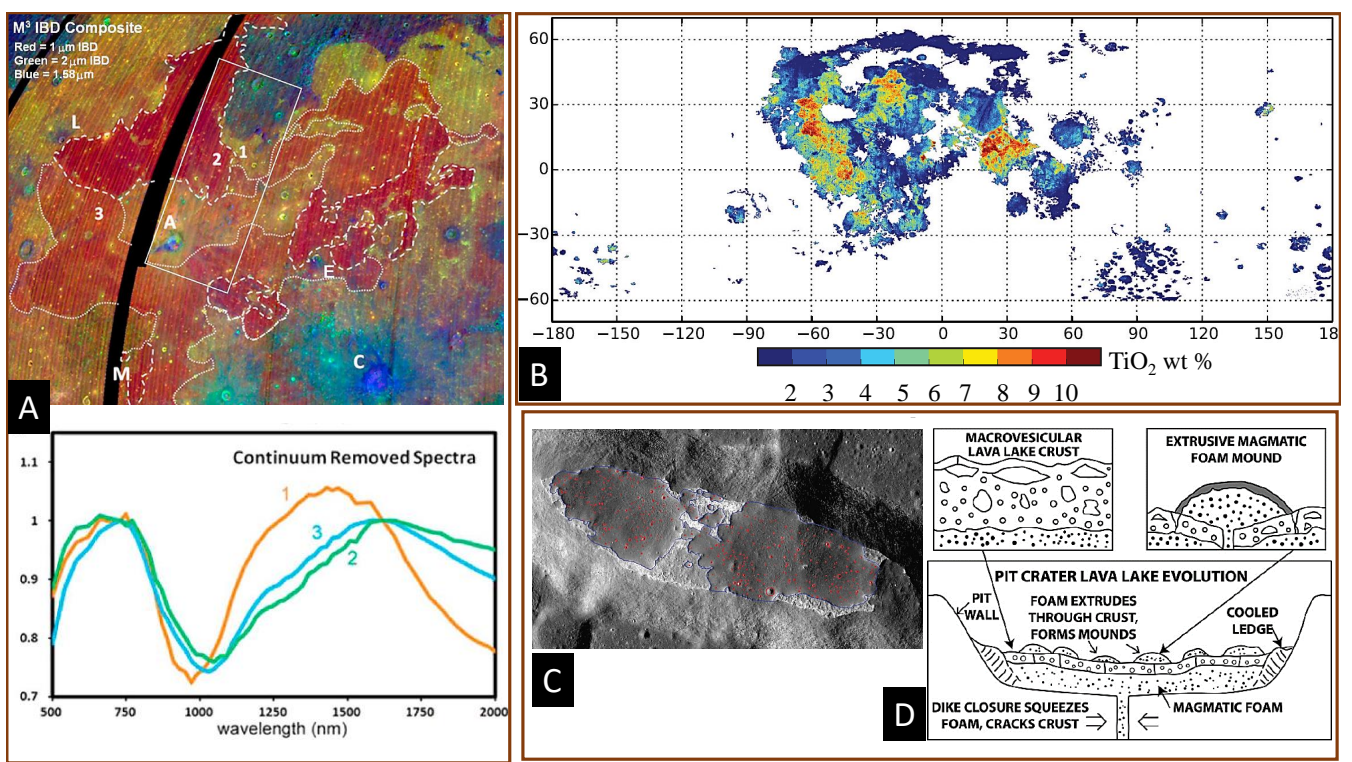

Figure 8. Insights from extrusive volcanic deposits. (A) Fine-scale spectral variability within western nearside basalts. The olivine abundant nature of the youngest high titanium basalts is exhibited (Source: [67]). \#1: Old and Low Titanium; \#2 Youngest and High Titanium; \#3 High Titanium. (B) Titanium abundance map of Mare basalts from modern sensors (Source: [160]). (C) Irregular Mare Patches (IMPs) such as Sosigenes, exhibit very few superposed craters (marked in red circles) and have been suggested to indicate very recent volcanic episode (Source: [144]). (D) Alternative model of IMPs explaining their young morphology (including absence of superposed craters) despite very old age (Source: [149]). 


\subsubsection{Lunar Pyroclastic Deposits}

Extrusive magmatism in the form of pyroclastic eruptions has been well-recognized, and detailed studies of regional pyroclastic deposits are well-documented (e.g., [172,173]). The knowledgebase, however, has been getting enriched with new insights from recent missions including chromium-rich spinel detection at Sinus Aestuum $[174,175]$ and the hydrated nature of several of the pyroclastic deposits (e.g., [80]). There are also smaller, pyroclastic deposits that have been observed under different geologic settings including the floors of impact craters (e.g., [176]). These small deposits have now been studied in great detail by integration of radar, thermal infrared, visible, infrared and topographical datasets revealing wide range in glass content $(0-80 \mathrm{wt} \%)$, rock abundance and circular polarization ratio (e.g., [177]). These studies report greater general diversity in physical and mineralogical properties of small pyroclastic deposits compared to the larger deposits. This might be hinting at larger influence of local materials on small pyroclastic deposits. Till recently, a poorly understood aspect of lunar pyroclastic deposits was the nature of the driving agent (gas), especially given the earlier thinking that assumed a dry lunar interior. Even with the discovery of volatiles in the lunar interior, it has been suggested that $\mathrm{H}_{2} \mathrm{O}$ concentrations alone are insufficient to cause the observed pyroclastic eruptions, and therefore the chemical species contributing to the lunar pyroclastic eruptions need to be identified (e.g., [178]). Recent experimental work has suggested iron pentacarbonyl as the dominant species (with smaller concentrations of methane) that likely participated in the pyroclastic activity on the Moon (e.g., [179]).

\subsubsection{Lava Tube Skylights—Accessibility, Science and Resource Potential}

The discovery of lunar lava tube skylights/lunar pits has been a key finding in the last decade, enabled by high spatial resolution views of mare basalts by multiple missions (e.g., [180-182]). Several skylights have now been detected, including occurrences in the Mare Tranquillitatis and Marius Hills region (Figure 9). These lava tubes hold great scientific and resource potential. With documented lateral extent of $\sim 20 \mathrm{~m}$, exposure of several basalt layers and capacity to shield the interior from harmful solar radiation, the lava tubes could potentially provide future lunar habitats for astronauts and access to the geological records of lava outpourings (e.g., $[181,183,184])$. However, the limited information on skylights from remote sensing observations also adds several uncertainties, including the stability of the structure, lateral extent (and its connectivity) and potential hazards of unknown nature. Several studies including structural modeling and reconnaissance mission planning have been carried out to characterize the skylights, to be able to fully evaluate their potential and future uses (e.g., [185-189]). Lunar (collapse) pits have also been documented in impact melt deposits and might offer locations for future habitats. Emplacement of mare basalts took place in a series of eruptions over long geological time, with hiatuses in-between. High spatial resolution imaging datasets and subsurface information from ground penetrating radar are providing new views of distinctive basalt layers, which is important for variety of purposes, including estimation of the volume of outpouring during various volcanic episodes (e.g., [190]). 

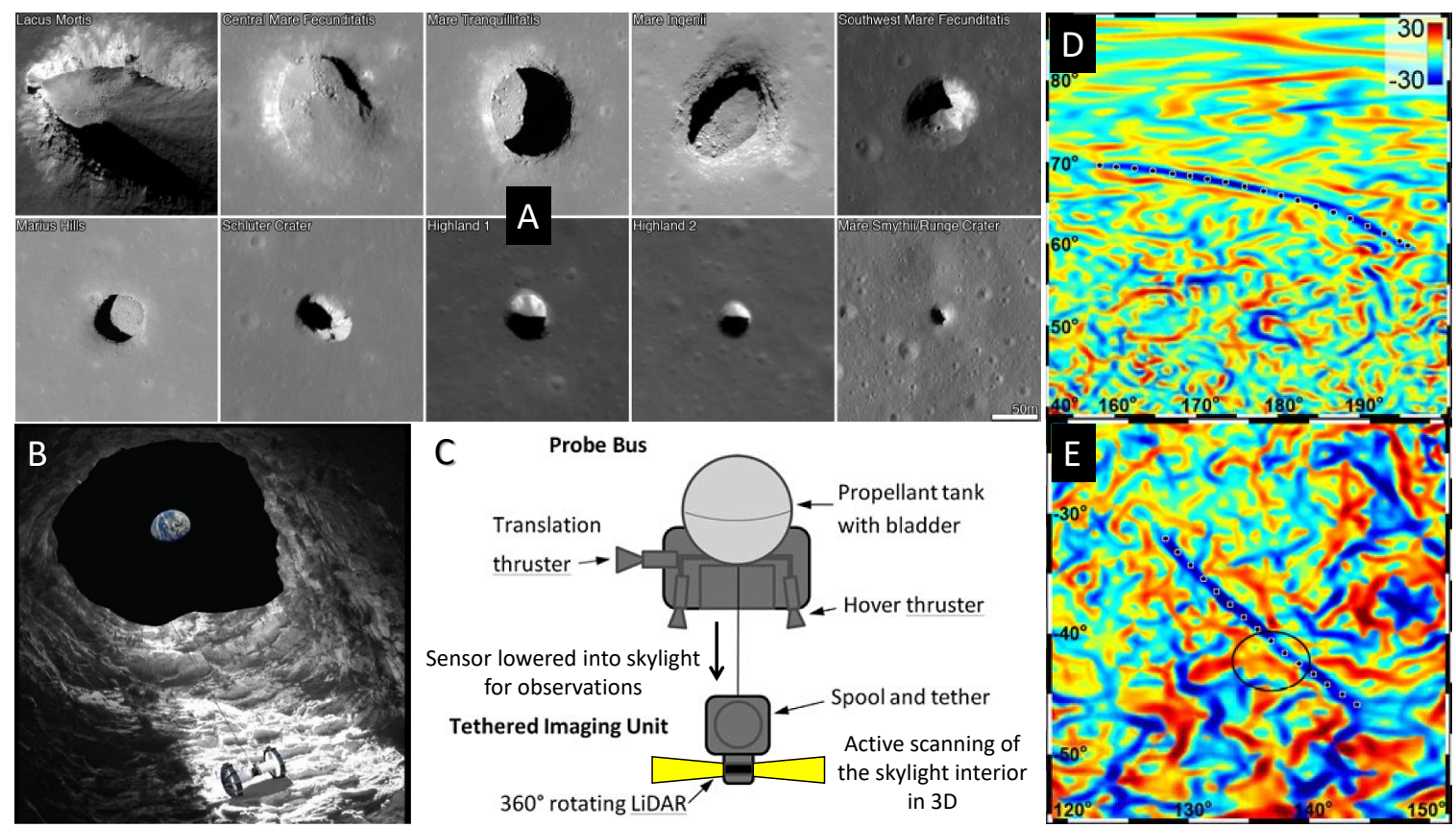

Figure 9. New views of lunar magmatic structures. (A) Lava tube skylights located in different parts of the Moon, enabled by high spatial resolution observations (Source: [184]). (B,C) Mission concepts for the exploration of lava tube skylights (Source: [188], modified from [189]). (D,E) Linear gravity anomalies (LGAs) of large spatial extent (several hundred $\mathrm{km}$ ) have been interpreted to be ancient magmatic Intrusions (Source: [191]).

\subsubsection{Intrusive Magmatism}

Magmatic activity on the Moon in the form of intrusive deposits has been documented largely from lunar samples and hinted by remote sensing observations in the past (e.g., [192,193]). This data record is not only important in understanding the lunar evolution in general but is also required for answering some important questions. One key enigma has been the asymmetric distribution of mare basalts between the near and the far side. Recent geophysical observations have discovered linear gravity anomalies (LGAs) on the Moon, some of them with a lateral extent of a few hundred kilometers and width of a few kilometers (Figure 9) (e.g., [191]). LGAs occur extensively both on the near and far side of the Moon and have been interpreted as ancient magmatic intrusions, produced during the early phase of lunar evolution when the Moon was in a state of globally isotropic extensional stress. If true, these observations not only provide key insights into the thermal evolution of the Moon far back in the geological time, the global occurrence also provides strong evidence of extensive magmatism on both the near and far side of the Moon. The crustal thickness variations likely led to stalling of magmatic bodies within the farside crust (and likely at some locations on the nearside). These observations thus provide fresh insights on the global magmatic activity on the Moon, as opposed to the magmatic activity exhibited by asymmetric occurrence of extrusive volcanism.

The nature of the Procellarum region has been debated for a long time with impact as the likely mode of its origin (e.g., [43,194,195]). High quality gravity data has now provided new perspectives with the identification of positive, narrow, linear gravity anomalies bordering the region in a non-circular and non-elliptical geometry, which is contrary to the expectation in the case of an impact origin (e.g., [196,197]). The study further suggests that the gravity anomalies represent lava-filled weak zones produced in response to large scale thermal stresses in that region. The high concentration of heat producing elements in the Procellarum region is believed to have caused differential cooling in the region and have thus influenced the distribution of thermal stresses. However, the cause of localization of heat producing elements in the Procellarum region is still not well understood. 
Floor-fractured craters (FFCs) have long been suggested to be potential evidence for near-surface intrusive activity, although viscous relaxation has also be been proposed as an alternative (e.g., [192,198]). Integrated morphological, topographic and gravity analyses along with physical modeling of FFCs using data from recent missions has enabled several new insights while also revealing the associated challenges with the available observations. The studies strongly support near-surface intrusive activity as the cause for the formation of FFCs. Accordingly, a viscous relaxation mechanism is no longer supported for the origin of FFCs. In addition, the studies have also revealed that, although high quality gravity data broadly correlates with the occurrences of small magmatic intrusions within FFCs, the correlation is not strong enough due to significantly smaller gravity signal from such intrusions (e.g., [199-201]). Future missions and/or better techniques would hopefully provide better tools for studying the floor-fractured craters.

\subsection{Compositional Trends within Anorthositic Crust—Lateral and Vertical}

The compositional character of the lunar primary crust exhibits rich diversity both in the lateral and vertical dimensions, holding important clues to the evolutionary history of the Moon. It includes the geological activity during the cooling of magma ocean and subsequent to its solidification. Material and energy contributions from both external and internal agents have been the driving factors in the continuous modification of the primordial lunar crust over the last several billions of years. The unobstructed global excess to the topmost surface of the lunar crust (through remote sensing observations) has provided an enormous amount of scientific insight into the workings of the various geological processes, as well as their influence on the crustal framework. There are two broad crustal components which enable the understanding of the different aspects of crustal evolution. Overlaps are however unavoidable and bring in the complexity in observation and their interpretations.

\subsubsection{Primordial Crust Produced (and Modified) Dominantly by Internal Geological Activities}

The primordial crust extracted from the magma ocean differentiation has been suggested to be stratified, including an impure plagioclase-rich layer (with mafic components) and pure plagioclaserich layer (almost devoid of mafics). The exact stratigraphic order of various plagioclase layers is not well constrained, but this character of the primordial crust has led to the general expectation of change in mafic character with depth. However, the primordial crust, as a function of its global occurrence and large time span of formation, was likely being simultaneously modified by internal geological activities at different spatial scales. Large scale events such as mantle overturn, along with localized partial melting, ascent and eruption of magmas, have certainly led to extensive physical and chemical interactions with the primordial crust. The current mineralogical character of the crust (Figure 10) is in part an outcome of these processes.

Discovery of Mg-spinel rich lithologies, in the form of Pink Spinel Anorthosite (PSA) on the near and far side lunar crust has been a major new finding from recent remote sensing data (e.g., [202-204]). The occurrence of this new rock type in variety of geological settings on the Moon possibly suggests more than one mode of origin. However, one of the current hypotheses has linked its origin to magma-wallrock interactions in the lower crust, with the character of the magma body being highly magnesian (e.g., [170]). This is consistent with the geological association of this lithology in many cases with the basin rings. However, possible formation through impact melt interactions with anorthositic rocks has also been suggested (e.g., $[205,206])$. One of the enigmatic findings of this lithology is an association with highly silicic rocks at Hansteen alpha (e.g., [204,207]). Integrated elemental, mineralogical and high resolution imaging results have indicated that $\mathrm{Mg}$-spinel exposures on Hansteen alpha are restricted to low Fe, pitted unit (absolute model age: $\sim 3.5$ billion years) and morphologically associated with ridges along scalloped features (e.g., [208,209]). It has been suggested that the Mg-spinel exposures might not be genetically related to the silicic lithology at Hansteen alpha. 

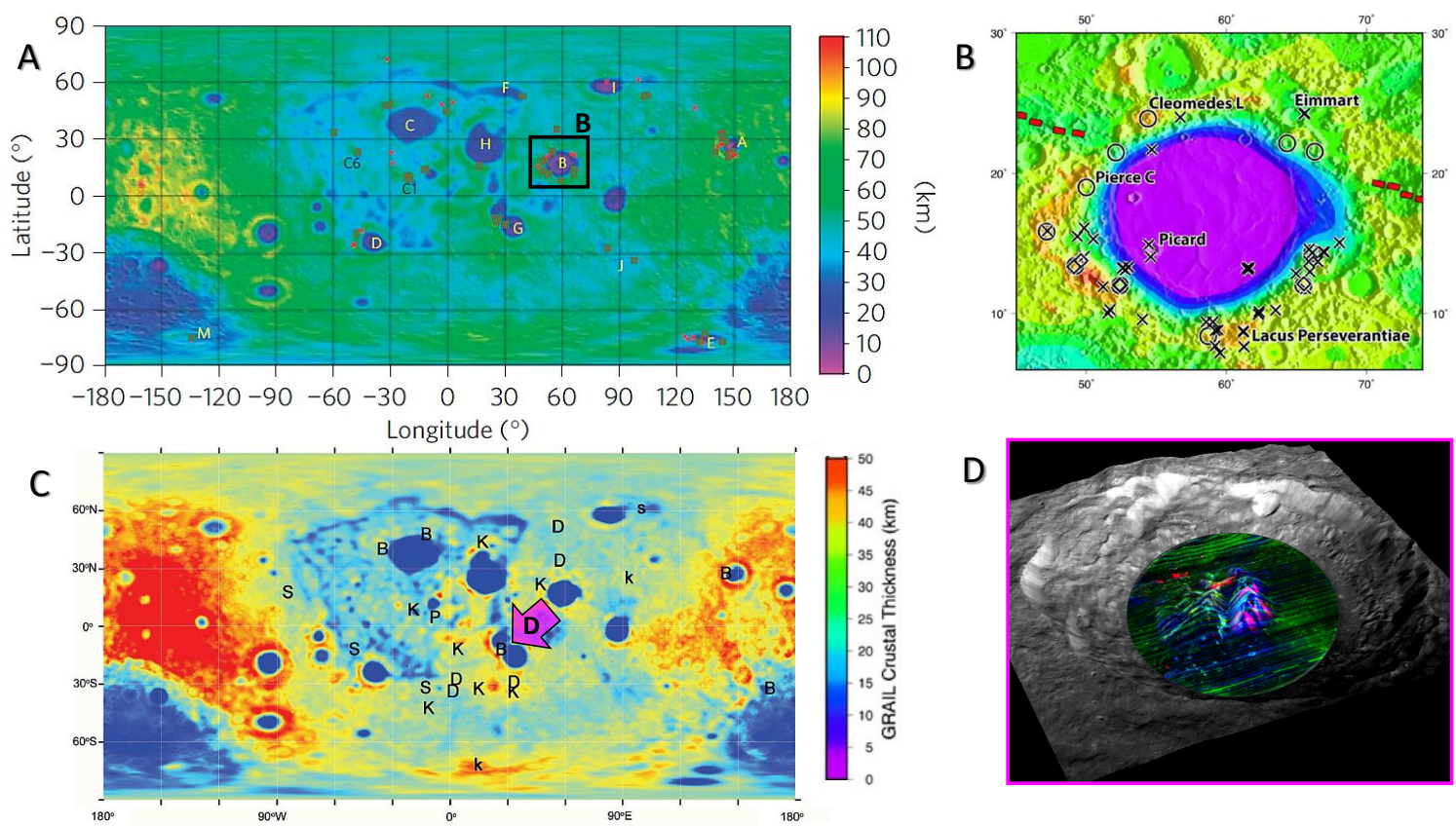

Figure 10. Global distribution of minerals with high resolution geologic context. (A) Preferential distribution of olivine exposures around impact basins. Possible mantle origin has been suggested based on detailed analyses (Source: [210]). (B) Olivine exposures at Crisium basin (shown by various symbols). Anomalously high concentration of olivine-bearing exposures is documented. Diverse origins have been proposed. Base map is crustal thickness overlain on topography. Red dotted line corresponds to GRAIL defined linear gravity anomaly. (Source: [211]). (C) Distribution of Mg-Spinel Anorthosite, the new rock type on the Moon. Preferential occurrence around basins and locations of low crustal thickness has been suggested. The pink arrow marks the location of Theophilus crater, shown in D (Source: [204]). The different letters refer to geologic setting (B-Basin, D-Dispersed, $\mathrm{K}$-Knobs, P-Pyroclastic, S-Special). (D) Mg-Spinel exposures (red and pink) concentrated in the central peaks of Theophilus crater (Source: Modified after [203]). Red, Green and blue colors represent band strength at $2 \mu \mathrm{m}, 1 \mu \mathrm{m}$ and $1.25 \mu \mathrm{m}$, respectively.

Global distribution of various key mineralogical endmembers (low Ca-pyroxene, high Ca-pyroxene, olivine and $\mathrm{Mg}$-spinel) has been mapped by several workers using a variety of datasets in order to identify and understand global and regional trends (Figure 10). In this context, occurrence of abundant olivine exposures around major basins has been suggested to indicate their possible mantle origin (e.g., [210]). If true, these locations could be important sampling locations for obtaining mantle rocks by future missions. Several follow-up studies using a variety of datasets and techniques, including spectral reflectance, thermal infrared and radiative transfer modeling, have highlighted the complexity of the character of the reported olivine occurrences with wide variation in the forsterite concentrations and likely multiple origins of olivine at different locations (e.g., [211,212]). Some studies have also supported the potential mantle origin of the reported locations based on numerical simulations of large impact events (e.g., [213]). The distribution of low Ca-pyroxene rich lithologies has highlighted some new observations. Highly magnesian $(\mathrm{Mg}>\sim 80)$ low Ca-pyroxene exposures have been located south of Mare Frigoris based on remote sensing observations and spectral modeling. A potential linkage with KREEP related Mg-suite pyroxenes has been suggested (e.g., [214]). The global distribution of high calcium-pyroxene in the highlands has revealed geologically interesting trends. Many of the geological young, small rayed-craters (8-24 km diameter) in the highlands region have high Ca-pyroxene as the dominant lithology (e.g., [215]). It has been suggested that the conventional thought that low-Ca pyroxene is the major mafic component of the crust may not be applicable universally. 


\subsubsection{Impact Cratering Produced Components at Local Scale}

Impacts have been gardening the lunar crust throughout geological time with varying intensity (Figure 11). The large-scale distribution of crater ejecta on the lunar surface is quite evident by the enormous rays of geologically young craters. As a result, lithologies occurring within the crust might actually be sourced from different depths and lead to a heterogeneous crustal framework rather than a well-defined compositionally layered structure. However, there may be exceptions, as in the case of exposure of possibly layered magmatic plutons (e.g., [193,202]). Apart from simple excavation and re-distribution of material during the cratering process, a melt component is also produced which increases with the size of the crater (i.e., larger craters have proportionately large deposits of impact melt) (e.g., [216]). High spatial resolution datasets at multiple wavelengths (viz. optical, thermal, radar) from recent missions have increasingly revealed extensive occurrence of impact melt deposits around impact craters and sometimes away from them (e.g., [217-222]). Impact melt deposits have conventionally been assumed to be rich in glass [223]. However, recent laboratory measurements have highlighted that impact melt signatures span from glass to completely crystalline, the latter mimicking signatures of primary igneous rocks (e.g., [224]). Detailed remote sensing studies characterizing the mineralogical character of morphologically identifiable impact melt deposits have revealed the crystalline nature of impact melt to be much more common than its glassy flavor (e.g., [225-227]). This crystalline character of impact melt deposits has important implications for the observed compositional diversity of the lunar crust and may therefore be an important component of the crust [228]. In the context of olivine mineralogy, it has recently been suggested that at least one exposure of olivine at Copernicus crater might have an impact melt origin, as opposed to being a primary exposure from mantle or crustal pluton (e.g., [229]). This finding also has direct bearing on the suggested mantle origin of olivine occurrences around basins discussed in the previous section.

\subsubsection{Impact Cratering Produced Components in Large Impacts}

Large impacts approaching the size of basins have significantly different implications for crustal compositional diversity and are therefore being discussed in a separate section. Compared to small impacts (simple to complex craters) where impact melt largely comprises of melt-rock mixtures, basins have a considerably larger molten component that may give rise to impact melt seas. It has been suggested (and argued against) that such large bodies of melt could potentially differentiate, giving rise to lithologies with igneous textures and more importantly indistinguishable signatures in remote sensing observations (e.g., [230-232]). If true, at least some of the observed crustal diversity may be the result of differentiated impact melt rather than primary igneous processes. This possibility of differentiated impact melt has been evaluated through petrological modeling, as well as direct validation of the predicted compositional stratigraphy through elemental and mineralogical assessment of impact melt seas at large basins. Petrological models have demonstrated the feasibility of impact melt differentiation and predicted the lithological succession and abundances [233,234]. Compositional studies of Orientale impact melt deposits have, however, shown to be not consistent with predicted lithologies from a differentiated impact melt (e.g., [235]). Similar studies have also been carried out for the South Pole Aitken (SPA) basin (discussed below). Although far from being resolved, the complexity of the problem and its significant implications strongly justifies the need for intensive studies of impact melt differentiation and impact cratering process at large spatial scale. 

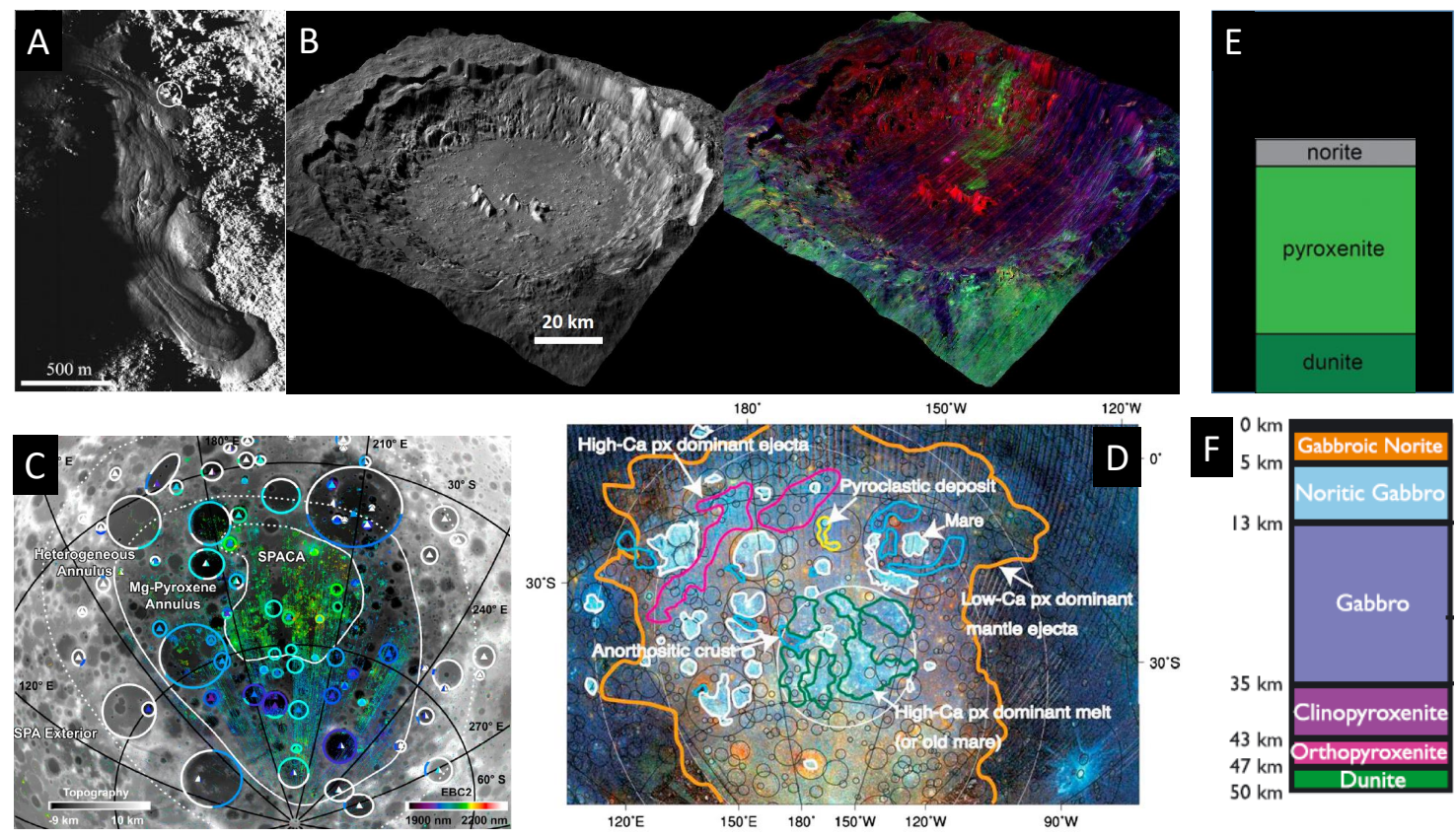

Figure 11. New views of impact melt deposits and SPA Basin. (A) High spatial resolution view of an impact melt flow deposit at Giordano Bruno crater (Source: [217]). (B) Unique impact melt flow feature with no detectable topographic signatures (left panel), which is compositionally distinct (green feature on crater floor and northern wall) from surrounding impact melt on the floor (after [226]). Red, green and blue colors map band strength at $1 \mu \mathrm{m}, 1.9 \mu \mathrm{m}$ and $2.3 \mu \mathrm{m}$ respectively. (C,D) Compositional zones at South Pole Aitken (SPA) basin (Source: $[236,237]$ ). (E,F) Modeled mineralogical sequence at SPA based on the differentiation of an assumed impact melt sea (Source: $[233,234]$ ).

\subsection{South-Pole Aitken Basin-New Light on the Lower Crust and Upper Mantle}

The oldest and the deepest impact basin on the Moon holds crucial clues to the earliest phase of the lunar evolution. Several new insights have been obtained from modern sensors at multiple wavelengths. Integrated mineralogy, elemental composition and topography data have revealed identifiable zones of different lithologies. An elevated region near the basin center, previously referred to as olivine hill [238] has now been confirmed to be rich in mafic minerals and accordingly referred to as mafic mound. The innermost zone in the SPA basin is composed of high calcium-pyroxenes and named the SPA compositional anomaly (SPACA) (e.g., [236,237]). However, some of the crater central peaks in this region exhibit low Ca-pyroxene mineralogy. The depth of origin for the central peaks provide constraints on the vertical extent of $\mathrm{Ca}$, Fe-rich pyroxene layer. The outer zone of SPA (still within the basin) is comprised of an annulus of Mg-rich pyroxenes. The compositional stratigraphy exposed at SPA has been compared to a differentiated impact melt, exposure of mantle material, as well as a product of a unique mode of non-mare volcanism (e.g., $[237,239])$. The lack of olivine-rich exposures within SPA has also led to the speculation that the mantle of the Moon is not olivine-rich, rather rich in low Ca-pyroxene (e.g., $[237,240])$. Detailed studies of low Ca-pyroxenes at SPA have also revealed composition of $\mathrm{Mg}_{50-70}$, suggesting that the SPA impact event excavated an iron-rich pyroxene (e.g., [214]). The study, however, also revealed that the exposures of low Ca-pyroxenes at Apollo basin (located within SPA) are different in character and likely more primitive in nature.

\section{Future Lunar Science and Exploration}

The Moon has been a cornerstone for understanding the solar system's evolution. The results from recent missions have provided brand new insights and have raised important new questions whose implications go beyond the Moon. Active attempts are being made worldwide to address some of these new questions, as well as old, unresolved questions through orbiters, landers and sample 
return missions (Figure 12). Several missions from national space agencies are in advanced stages of execution, including Chang'E-4 (first far side landing) and Chang'E-5 mission (sample return mission), Chandrayaan-2 (first landing at lunar high latitudes) and Lunar flashlight (multi-laser probing of the lunar poles in CubeSat architecture) (e.g., [100,241-243]). Several other missions are being currently planned or have been proposed, including LunaGlob, a mission to the lavatube skylights and the magnetic anomalies (e.g., [185,188,189,244,245]). Apart from the science of the Moon, one of the potential opportunities is to carry out science from the Moon (e.g., [246]). A key advancement in the field of lunar exploration has been the active participation of the private enterprise, which is probably key to maintaining a sustained presence on the Moon. Several companies, including Team Indus (India), Astrobotics (USA), Moon Express (USA) and ILS (Israel) have made sustained efforts for more than a decade to make private Moon landing a possibility (e.g., [247-252]). Although, such a milestone has not yet been achieved, its probability in the near future has been steadily rising. In addition, active efforts are also being made towards exploring the utilization of lunar material towards future infrastructural requirements (e.g., [253-256]).

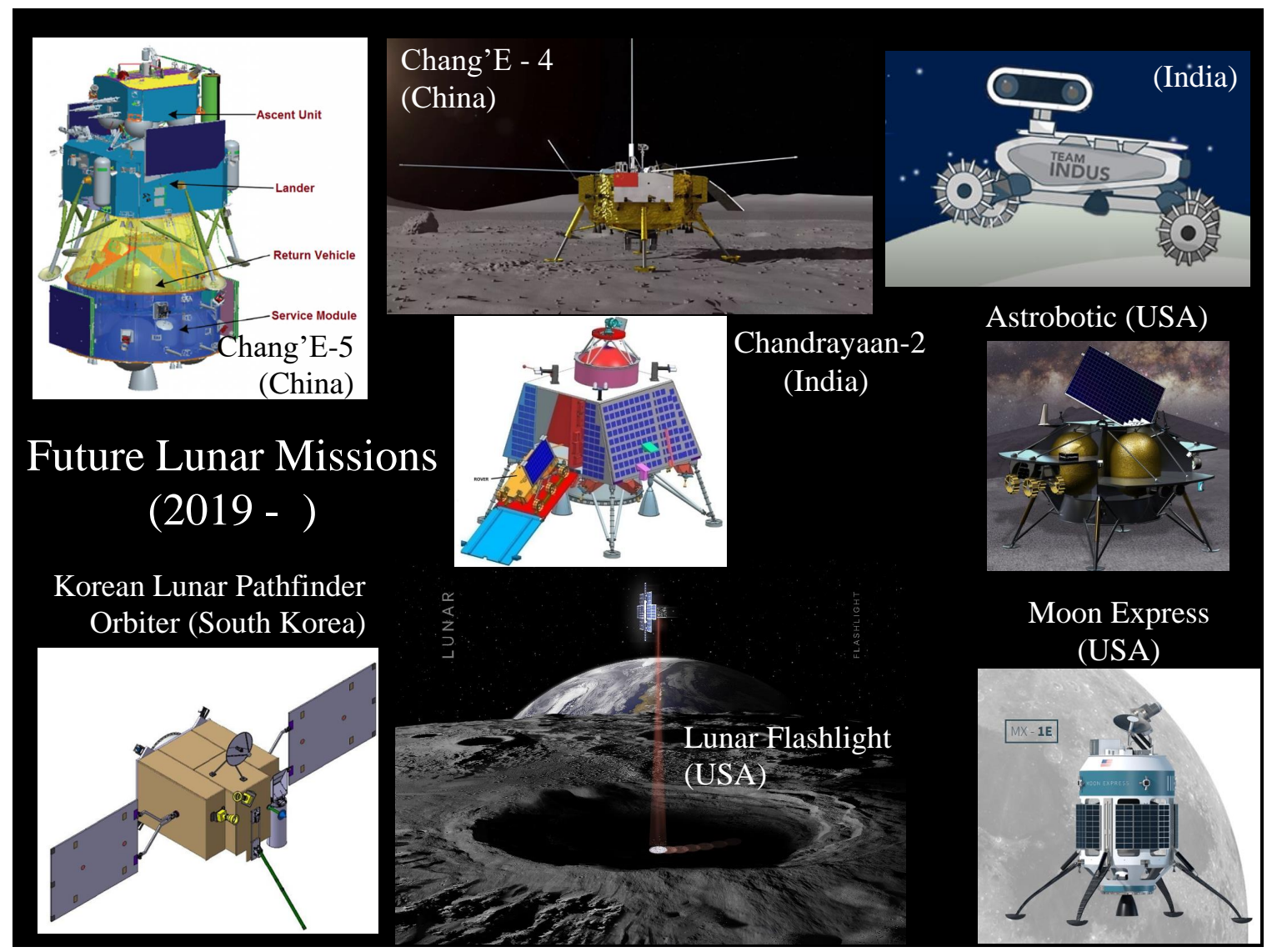

Figure 12. Lunar missions in the near future (planned/proposed). Credits for individual images: CNSA, KARI, NASA, ISRO, Team Indus, Astrobotic and Mars Express.

\section{Summary}

Significant scientific discoveries have been made in the last decade that have revolutionized the understanding of the Moon, raising critical questions about the origin of the Moon through a large impact, its evolution in a magma ocean scenario, its volcanic and plutonic activity, as well as the primary, secondary and tertiary nature of the lunar crust. The discoveries of the three types of volatiles (a monolayer of $\mathrm{OH} / \mathrm{H}_{2} \mathrm{O}$, polar ice and magmatic water in the lunar interior) have important implications for the Moon and beyond, and have dramatically altered the scope of volatiles in the solar system. Extensive observational evidence for the pure plagioclase layer has provided tighter constraints 
on the nature of the magma ocean crystallization but also posed the challenging petrological problem of forming such a pure layer. The volcanic history of the Moon has been substantially revised through the availability of high resolution imaging, while also raising intense debates on the potentially very young volcanism. Brand new gravity observations have revealed the magmatic-intrusion-laden lunar crust providing great insights into the lunar thermal evolution in its early phases. New components of the crust in terms of pink spinel anorthosite (PSA) have been identified, sparking ideas about a KREEP-free Mg-suite, including the possibility of Mg-suite volcanic inventory. Several new perspectives on the impact process and products have been obtained, with the possibility of crustal compositional diversity being strongly influenced by recrystallized impact melt rocks at different spatial scales. The detection of volatiles on the lunar poles through multiple techniques, along with discovery of several lava tube skylights, have significantly revived the interest in lunar exploration and a sustained presence on the Moon. Approved, planned and proposed new missions promise great hope for science and exploration of the Moon in the immediate and distant future. The Moon continues to demonstrate its great scientific potential and promise as an exploration outpost with potential resources for sustaining long-term presence. An ancient saying (Figure 13) from an Indian scripture captures the human scientific curiosity and the acknowledgement of the Moon's ability to provide answers to some of the outstanding questions in planetary science:

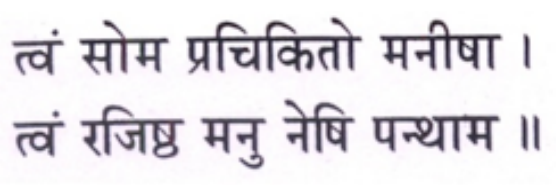

\section{O Moon! \\ We should be able to know you Through our intellect You enlighten us through the right path}

$\dot{R}$ gveda part $-I / 91 / 1$

Figure 13. A Sanskrit shloka (verse) from an ancient Indian scripture, Rigveda, originating in $\sim 1500$ BCE. Credit: ISRO Somayaan Project Report.

Funding: This research received no external funding.

Acknowledgments: We wish to thank the two anonymous reviewers and the academic editor for their comments and suggestions which have improved the manuscript.

Conflicts of Interest: The author declares no conflict of interest.

\section{References}

1. Tera, F.; Papanastassiou, D.A.; Wasserberg, G.J. Isotopic evidence for a terminal lunar cataclysm. Earth Planet. Sci. Lett. 1974, 22, 1-21. [CrossRef]

2. Wood, J.A.; Dickey, J.S., Jr; Marvin, U.B.; Powell, B.N. Lunar anorthosites and a geophysical model of the Moon. In Proceedings of the Apollo 11 Lunar Science Conference, Houston, TX, USA, 5-8 January 1970; pp. 968-988.

3. Hartmann, W.K. Early lunar cratering. Icarus 1966, 5, 406-418. [CrossRef]

4. Hartmann, W.K. Lunar crater counts. VI: The young craters Tycho, Aristarchus, and Copernicus. Commun. Lunar Planet. Lab. 1968, 8, 145-156.

5. Neukum, G.; König, B. Dating of individual lunar craters. In Proceedings of the 7th Lunar Science Conference, Houston, TX, USA, 15-19 March 1976; pp. 2867-2881.

6. Neukum, G.; Ivanov, B.A.; Hartmann, W.K. Cratering records in the inner solar system in relation to the lunar reference system. Space Sci. Rev. 2001, 96, 55-86. [CrossRef]

7. Ivanov, B.A. Mars/Moon cratering rate ratio estimates. Space Sci. Rev. 2001, 96, 87-104. [CrossRef]

8. Kreslavsky, M.A.; Asphaug, E. Direct Delivery of Lunar Impact Ejecta to the Earth. In Proceedings of the 45th Lunar and Planetary Science Conference (LPSC), Woodlands, TX, USA, 17-21 March 2014; p. 2455. 
9. Bottke, W.F.; Vokrouhlický, D.; Marchi, S.; Swindle, T.; Scott, E.R.D.; Weirich, J.R.; Levison, H. Dating the Moon-forming impact event with asteroidal meteorites. Science 2015, 348, 321-323. [CrossRef] [PubMed]

10. Hartmann, W.K.; Davis, D.R. Satellite-sized planetesimals and lunar origin. Icarus 1975, 24, 504-515. [CrossRef]

11. Cameron, A.G.W.; Ward, W.R. The origin of the Moon. In Proceedings of the Lunar and Planetary Science Conference, Houston, TX, USA, 15-19 March 1976; Volume 7, pp. 120-122.

12. Cameron, A.G.W. Higher resolution simulations of the Giant Impact. In Origin of the Earth and Moon; Righter, K., Canup, R., Eds.; University of Arizona Press: Tucson, AZ, USA, 2000; pp. 133-144.

13. Canup, R.M.; Asphaug, E. Origin of the Moon in a giant impact near the end of Earth's formation. Nature 2001, 412, 708-712. [CrossRef] [PubMed]

14. Ćuk, M.; Stewart, S.T. Making the Moon from a Fast-Spinning Earth: A Giant Impact Followed by Resonant Despinning. Science 2012, 338, 1047-1052. [CrossRef] [PubMed]

15. Canup, R.M. Forming a Moon with an Earth-like Composition via a Giant Impact. Science 2012, 338, 1052-1055. [CrossRef] [PubMed]

16. Rufu, R.; Aharonson, O.; Perets, H.B. A multiple-impact origin for the Moon. Nat. Geosci. 2017, 10, 89-94. [CrossRef]

17. Gilbert, G.K. The Moon's face: A study of the origin of its features. Philos. Soc. Wash. 1893, 12, 241-292.

18. Marshall, R.K. Origin of the lunar craters, a summary. Pop. Astron. 1943, 51, 415-424.

19. Kuiper, G.P. On the origin of the lunar surface features. Proc. Natl. Acad. Sci. USA 1954, 40, 1096-1112. [CrossRef] [PubMed]

20. Baldwin, R.B. The Face of the Moon; University of Chicago Press: Chicago, IL, USA, 1949.

21. Baldwin, R.B. The Measure of the Moon; University of Chicago Press: Chicago, IL, USA, 1963.

22. Urey, H.C. Origin and history of the Moon. In Physics and Astronomy of the Moon; Kopal, Z., Ed.; Academic Press: New York, NY, USA, 1962; pp. 481-523.

23. Goldreich, P. History of lunar orbit. Rev. Geophys. 1966, 4, 411-439. [CrossRef]

24. Storm, R.G.; Fielder, G. Multiphase development of lunar crater Tycho. Nature 1968, 217, 611-615. [CrossRef]

25. Green, J. Copernicus as a Lunar Caldera. J. Geophys. Res. 1971, 76, 5719-5731. [CrossRef]

26. Barricelli, N.A.; Metcalfe, R. The lunar surface and early history of the Earth's satellite system. Icarus 1969, 10, 144-163. [CrossRef]

27. Turkevich, A.L.; Franzgrote, F.J.; Patterson, J.H. Chemical compositions of the lunar surface Mare Tranquillitatis. Science 1969, 165, 277-279. [CrossRef] [PubMed]

28. Rhodes, J.M.; Hodges, F.N.; Papike, J.J. Mare basalts major element composmon and classification. In Proceedings of the Origins of Mare Basalts and Their Implications for Lunar Evolution, Lunar Science Institute, Houston, TX, USA, 17-19 November 1975; pp. 135-139.

29. Metzger, A.E.; Parker, R.E. The distribution of titanium on the lunar surface. Earth Planet. Sci. Lett. 1979, 45, 155-171. [CrossRef]

30. Davis, P.A. Iron and titanium distribution on the Moon from orbital gamma-ray spectrometry with implications for crustal evolutionary models. J. Geophys. Res. 1980, 85, 3209-3224. [CrossRef]

31. Pieters, C.M.; McCord, T.B. Characterization of lunar mare basalt types: A remote sensing study using reflection spectroscopy of surface soils. In Proceedings of the 7th Lunar Science Conference, Houston, TX, USA, 15-19 March 1976; pp. 2677-2690.

32. Johnson, T.V.; Saunders, R.S.; Matson, D.L.; Mosher, J.A. A $\mathrm{TiO}_{2}$ abundance map for the northern maria. In Proceedings of the 8th Lunar Science Conference, Houston, TX, USA, 14-18 March 1977; pp. 1029-1036.

33. Pieters, C.M. Mare basalt types on the front side of the Moon: A summary of spectral reflectance data. In Proceedings of the 9th Lunar and Planetary Science Conference, Houston, TX, USA, 13-17 March 1978; pp. 2825-2849.

34. Pieters, C.M. Copernicus Crater Central Peak: Lunar Mountain of Unique Composition. Science 1982, 215, 59-61. [CrossRef] [PubMed]

35. Hapke, B.; Cassidy, W.; Wells, E. Effects of vapor-phase deposition processes on the optical, chemical, and magnetic properties of the lunar regolith. Moon 1975, 13, 339-353. [CrossRef]

36. Head, J.W. Lunar volcanism in space and time. Rev. Geophys. 1976, 14, 265-300. [CrossRef]

37. Warren, P.H.; Wasson, J.T. The origin of KREEP. Rev. Geophys. 1979, 17, 73-88. [CrossRef] 
38. May, T.W.; Peeples, W.J.; Maxwell, T.; Sill, W.R.; Ward, S.H.; Phillips, R.J.; Jordan, R.; Abbott, E. Subsurface Layering in Maria Serenitatis and Crisium: Apollo Lunar Sounder Results. In Proceedings of the Lunar and Planetary Science Conference, Houston, TX, USA, 15-19 March 1976; Volume 7, p. 540.

39. Vaniman, D.; Dietrich, J.; Taylor, G.J.; Heiken, G. Exploration, samples and recent concepts of the Moon. In Lunar Sourcebook; Heiken, G., Vaniman, D., French, B.M., Eds.; Cambridge University Press: Cambridge, UK, 1993; pp. 5-26, 721.

40. Taylor, S.R. Planetary Science: A Lunar Perspective; Lunar and Planetary Institute: Houston, TX, USA, 1982; 481 .

41. Korotev, R.L. Pristine Cataclasite Anorthosite. Available online: http://meteorites.wustl.edu/lunar/apollo/ index.htm (accessed on 16 December 2018).

42. Seddio, S.M.; Jolliff, B.L.; Korotev, R.L.; Zeigler, R.A. Petrology and geochemistry of lunar granite 12032,366-19 and implications for lunar granite petrogenesis. Am. Mineral. 2013, 98, 1697-1713. [CrossRef]

43. Wilhelms, D.E. With Sections by McCauley, and Newell J. Trask The Geological History of the Moon; USGS: Reston, VA, USA, 1987; Volume 1348, pp. 1-302. [CrossRef]

44. Heiken, G.H.; Vaniman, D.T.; French, B.M. Lunar Sourcebook; Cambridge University Press: Cambridge, UK, 1993; p. 721.

45. Nozette, S.; Rustan, P.; Pleasance, L.P.; Kordas, J.F.; Lewis, I.T.; Park, H.S.; Priest, R.E.; Horan, D.M.; Regeon, P.; Lichtenberg, C.L.; et al. The Clementine Mission to the Moon: Scientific Overview. Science 1994, 266, 1835-1839. [CrossRef] [PubMed]

46. Binder, A.B. Lunar Prospector: Overview. Science 1998, 281, 1475-1476. [CrossRef] [PubMed]

47. Johnson, T.V.; Yeates, C.M.; Young, R. Space Science Reviews volume on Galileo Mission overview. In The Galileo Mission; Russell, C.T., Ed.; Springer: Dordrecht, The Netherlands, 1992; Volume 60, pp. 3-21.

48. Lucey, P.G.; Taylor, G.J.; Malaret, E. Abundance and distribution of iron on the Moon. Science 1995, 268, 1150-1153. [CrossRef] [PubMed]

49. Lucey, P.G.; Blewett, D.T.; Hawke, B.R. Mapping the $\mathrm{FeO}$ and $\mathrm{TiO}_{2}$ content of the lunar surface with multispectral imagery. J. Geophys. Res. 1998, 103, 3679-3699. [CrossRef]

50. Lucey, P.G.; Blewett, D.T.; Jolliff, B.L. Lunar iron and titanium abundance algorithms based on final processing Clementine UV-vis images. J. Geophys. Res. 2000, 105, 20297-20305. [CrossRef]

51. Blewett, D.T.; Lucey, P.G.; Hawke, B.R.; Jolliff, B.L. Clementine images of the lunar sample-return stations: Refinement of $\mathrm{FeO}$ and $\mathrm{TiO}_{2}$ mapping techniques. J. Geophys. Res. 1997, 102, 16319-16325. [CrossRef]

52. Jolliff, B.L.; Gillis, J.J.; Haskin, L.A.; Korotev, R.L.; Wieczorek, M.A. Major lunar crustal terranes: Surface expressions and crust-mantle origins. J. Geophys. Res. 2000, 105, 4197-4216. [CrossRef]

53. Nozette, S.; Lichtenberg, C.L.; Spudis, P.; Bonner, R.; Ort, W.; Malaret, E.; Robinson, M.; Shoemaker, E.M. The Clementine Bistatic Radar Experiment. Science 1994, 274, 1495-1498. [CrossRef]

54. Watson, K.; Murray, B.C.; Brown, H. The behavior of volatiles on the lunar surface. J. Geophys. Res. 1961, 66, 3033-3045. [CrossRef]

55. Arnold, J.R. Ice in the lunar polar regions. J. Geophys. Res. 1979, 84, 5659-5668. [CrossRef]

56. Feldman, W.C.; Maurice, S.; Binder, A.B.; Barraclough, B.L.; Elphic, R.C.; Lawrence, D.J. Fluxes of Fast and Epithermal Neutrons from Lunar Prospector: Evidence for Water Ice at the Lunar Poles. Science 1994, 281, 1496-1500. [CrossRef]

57. Elphic, R.C.; Lawrence, D.J.; Feldman, W.C.; Barraclough, B.L.; Maurice, S.; Binder, A.B.; Lucey, P.G. Lunar rare earth element distribution and ramifications for $\mathrm{FeO}$ and $\mathrm{TiO}_{2}$ : Lunar Prospector neutron spectrometer observations. J. Geophys. Res. 2000, 105, 20333-20345. [CrossRef]

58. Elphic, R.C.; Lawrence, D.J.; Feldman, W.C.; Barraclough, B.L.; Maurice, S.; Lucey, P.G.; Blewett, D.T.; Binder, A.B. The Lunar Prospector neutron spectrometer constraints on $\mathrm{TiO}_{2}$. J. Geophys. Res. 2002, 107. [CrossRef]

59. Konopliv, A.S.; Binder, A.B.; Hood, L.L.; Kucinskas, A.B.; Sjogren, W.L.; Williams, J.G. Improved Gravity Field of the Moon from Lunar Prospector. Science 1998, 281, 1476-1480. [CrossRef] [PubMed]

60. Tompkins, S.; Pieters, C. Mineralogy of the lunar crust: Results from Clementine. Meteor. Planet. Science 1999, 34, 25-41. [CrossRef]

61. Cahill, J.T.S.; Lucey, P.G.; Wieczorek, M.A. Compositional variations of the lunar crust: Results from radiative transfer modeling of central peak spectra. J. Geophys. Res. Planets 2009, 114. [CrossRef]

62. Schultz, P.H.; Spudis, P.D. The beginning and end of lunar volcanism. Nature 1983, 302, 233-236. [CrossRef] 
63. Hiesinger, H.; Head, J.W.; Wolf, U.; Jaumann, R.; Neukum, G. Ages and stratigraphy of mare basalts in Oceanus Procellarum, Mare Nubium, Mare Cognitum, and Mare Insularum. J. Geophys. Res. 2003, 108. [CrossRef]

64. Schultz, P.H.; Staid, M.I.; Pieters, C.M. Lunar activity from recent gas release. Nature 2006, 444, $184-186$. [CrossRef] [PubMed]

65. Hiesinger, H.; Head, J.W.; Wolf, U.; Neukum, G. Lunar mare basalts: Mineralogical variations with time. In Proceedings of the 32nd Lunar and Planetary Science Conference, Houston, TX, USA, 12-16 March 2001; Abstract \#1826.

66. Petro, N. More surprises from the Moon. Nat. Geosci. 2011, 4, 499-501. [CrossRef]

67. Staid, M.I.; Pieters, C.M.; Besse, S.; Boardman, J.; Dhingra, D.; Green, R.; Head, J.W.; Isaacson, P.; Klima, R.; Kramer, G.; et al. The mineralogy of late stage lunar volcanism as observed by the Moon Mineralogy Mapper on Chandrayaan-1. J. Geophys. Res. 2011, 116, E00G10. [CrossRef]

68. Saal, A.E.; Hauri, E.H.; Cascio, M.L.; Van Orman, J.A.; Rutherford, M.C.; Cooper, R.F. Volatile content of lunar volcanic glasses and the presence of water in the Moon's interior. Nature 2008, 454, 192-195. [CrossRef] [PubMed]

69. Hauri, E.H.; Weinreich, T.; Saal, A.E.; Rutherford, M.C.; Van Orman, J.A. High pre-eruptive water contents preserved in lunar melt inclusions. Science 2011, 333, 213-215. [CrossRef] [PubMed]

70. McCubbin, F.M.; Steele, A.; Hauri, E.H.; Nekvasil, H.; Yamashita, S.; Hemley, R.J. Nominally hydrous magmatism on the Moon. Proc. Natl. Acad. Sci. USA 2010, 7, 11223-11228. [CrossRef] [PubMed]

71. Barnes, J.J.; Tartèse, R.; Anand, M.; McCubbin, F.M.; Franchi, I.A.; Starkey, N.A.; Russell, S.S. The origin of water in the primitive Moon as revealed by the lunar highlands samples. Earth Planet. Sci. Lett. 2014, 390, 244-252. [CrossRef]

72. Hauri, E.H.; Saal, A.E.; Rutherford, M.J.; Van Orman, J.A. Water in the Moon's interior: Truth and consequences. Earth Planet. Sci. Lett. 2015, 409, 252-264. [CrossRef]

73. Boyce, J.W.; Tomlinson, S.M.; McCubbin, F.M. The lunar apatite paradox. Science 2014, 344, 400-402. [CrossRef] [PubMed]

74. Pahlevan, K.; Stevenson, D.J. Equilibration in the aftermath of the lunar-forming giant impact. Earth Planet. Sci. Lett. 2007, 262, 438-449. [CrossRef]

75. Pahlevan, K.; Karato, S.; Fegley, B. Speciation and dissolution of hydrogen in the proto-lunar disk. Earth Planet. Sci. Lett. 2016, 445, 104-113. [CrossRef]

76. Klima, R.; Cahill, J.; Hagerty, J.; Lawrence, D. Remote detection of magmatic water in Bullialdus Crater on the Moon. Nat. Geosci. 2013, 6, 737-741. [CrossRef]

77. Bhattacharya, S.; Saran, S.; Dagar, A.; Chauhan, P.; Chauhan, M.; Kumar, K. Endogenicwater on the Moon associated with non-mare silicic volcanism: Implications for hydrated lunar interior. Curr. Sci. 2013, 105, 685-691.

78. Bhattacharya, S.; Lal, D.; Chauhan, M.; Chauhan, P.; Ajai; Kumar, A.S.K. Detection of hydroxyl-bearing exposures of possible magmatic origin on the central peak of crater Theophilus using Chandrayaan-1 Moon Mineralogy Mapper (M3) data. Icarus 2015, 260, 167-173. [CrossRef]

79. Li, S.; Milliken, R.E. Water on the surface of the Moon as seen by the Moon Mineralogy Mapper: Distribution, abundance, and origins. Sci. Adv. 2017, 3, e1701471. [CrossRef] [PubMed]

80. Milliken, R.E.; Li, S. Remote detection of widespread indigenous water in lunar pyroclastic deposits. Nat. Geosci. 2017, 10, 561-565. [CrossRef]

81. Clark, R.N. Detection of adsorbed water and hydroxyl on the Moon. Science 2009, 326, 562-564. [CrossRef] [PubMed]

82. Pieters, C.M.; Goswami, J.N.; Clark, R.N.; Annadurai, M.; Boardman, J.; Buratti, B.; Combe, J.-P.; Dyar, M.D.; Green, R.; Head, J.W.; et al. Character and spatial distribution of $\mathrm{OH} / \mathrm{H}_{2} \mathrm{O}$ on the surface of the Moon seen by M3 on Chandrayaan-1. Science 2009, 326, 568-572. [CrossRef] [PubMed]

83. Sunshine, J.M.; Farnham, T.L.; Feaga, L.M.; Groussin, O.; Merlin, F.; Milliken, R.E.; A'Hearn, M.F. Temporal and spatial variability of lunar hydration as observed by the deep impact spacecraft. Science 2009, 326, 565-568. [CrossRef] [PubMed]

84. Sridharan, R.; Ahmed, S.M.; Das, T.P.; Sreelatha, P.; Kumar, P.P.; Naik, N.; Supriya, G. 'Direct' evidence for water $\left(\mathrm{H}_{2} \mathrm{O}\right)$ in the sunlit lunar ambience from CHACE on MIP of Chandrayaan I. Planet. Space Sci. 2010, 58, 947-950. [CrossRef] 
85. McCord, T.B.; Taylor, L.A.; Combe, J.-P.; Kramer, G.; Pieters, C.M.; Sunshine, J.M.; Clark, R.N. Sources and physical processes responsible for $\mathrm{OH} / \mathrm{H}_{2} \mathrm{O}$ in the lunar soil as revealed by the Moon Mineralogy Mapper (M3). J. Geophys. Res. 2011, 116, E00G05. [CrossRef]

86. Wöhler, C.; Grumpe, A.; Berezhnoy, A.A.; Shevchenko, V.V. Time-of-day-dependent global distribution of lunar surficial water/hydroxyl. Sci. Adv. 2017, 3, e1701286. [CrossRef] [PubMed]

87. Bandfield, J.L.; Poston, M.J.; Klima, R.L.; Edwards, C.S. Widespread distribution of $\mathrm{OH} / \mathrm{H}_{2} \mathrm{O}$ on the lunar surface inferred from spectral data. Nat. Geosci. 2018, 11, 173-177. [CrossRef] [PubMed]

88. Ichimura, A.S.; Zent, A.P.; Quinn, R.C.; Sanchez, M.R.; Taylor, L.A. Hydroxyl (OH) production on airless planetary bodies: Evidence from H+/D+ ion-beam experiments. Earth Planet. Sci. Lett. 2012, 345-348, 90-94. [CrossRef]

89. Spudis, P.D.; Bussey, D.B.J.; Baloga, S.M.; Butler, B.J.; Carl, D.; Carter, L.M.; Chakraborty, M.; Elphic, R.C.; Gillis-Davis, J.J.; Goswami, J.N.; et al. Initial results for the north-pole of the Moon from Mini-SAR, Chandrayaan-1 mission. Geophys. Res. Lett. 2010, 37, L06204. [CrossRef]

90. Colaprete, A.; Schultz, P.; Heldmann, J.; Wooden, D.; Shirley, M.; Ennico, K.; Hermalyn, B.; Marshall, W.; Ricco, A.; Elphic, R.C.; et al. Detection of Water in the LCROSS Ejecta Plume. Science 2010, 330, 463-468. [CrossRef] [PubMed]

91. Schultz, P.H.; Hermalyn, B.; Colaprete, A.; Ennico, K.; Shirley, M.; Marshall, W.S. The LCROSS Cratering Experiment. Science 2010, 330, 468-472. [CrossRef] [PubMed]

92. Mitrofanov, I.G.; Sanin, A.B.; Boynton, W.V.; Chin, G.; Garvin, J.B.; Golovin, D.; Evans, L.G.; Harshman, K.; Kozyrev, A.S.; Litvak, M.L.; et al. Hydrogen Mapping of the Lunar South Pole Using the LRO Neutron Detector Experiment LEND. Science 2010, 330, 483-486. [CrossRef] [PubMed]

93. Spudis, P.D.; Bussey, D.B.J.; Baloga, S.M.; Cahill, J.T.S.; Glaze, L.S.; Patterson, G.W.; Raney, R.K.; Thompson, T.W.; Thomson, B.J.; Ustinov, E.A. Evidence for water ice on the Moon: Results for anomalous polar craters from the LRO Mini-RF imaging radar. J. Geophys. Res. Planets 2013, 118, 2016-2029. [CrossRef]

94. Paige, D.A.; Siegler, M.A.; Zhang, J.A.; Hayne, P.O.; Foote, E.J.; Bennett, K.A.; Vasavada, A.R.; Greenhagen, B.T.; Schofield, J.T.; McCleese, D.J.; et al. Diviner Lunar Radiometer Observations of Cold Traps in the Moon's South Polar Region. Science 2010, 330, 479-482. [CrossRef] [PubMed]

95. Zuber, M.T.; Head, J.W.; Smith, D.E.; Neumann, G.A.; Mazarico, E.; Torrence, M.H.; Aharonson, O.; Tye, A.R.; Fassett, C.I.; Rosenburg, M.A.; et al. Constraints on the volatile distribution within Shackleton crater at the lunar south pole. Nature 2012, 486, 378-381. [CrossRef] [PubMed]

96. Gladstone, G.R.; Retherford, K.D.; Egan, A.F.; Kaufmann, D.E.; Miles, P.F.; Parker, J.W.; Horvath, D.; Rojas, P.M.; Versteeg, M.H.; Davis, M.W.; et al. Far-ultraviolet reflectance properties of the Moon's permanently shadowed regions. J. Geophys. Res. 2012, 117, E00H04. [CrossRef]

97. Lemelin, M.; Lucey, P.G.; Song, E.; Paige, D.A.; Greenhagen, B.T.; Siegler, M.A.; Hayne, P.O.; Mazarico, E.; Neumann, G.; Smith, D.E.; et al. A search for transient water frost at the lunar poles using LOLA. In Proceedings of the American Geophysical Union, Fall Meeting 2014, San Francisco, CA, USA, 15-19 December 2014. abstract id.P13D-3832.

98. Hayne, P.O.; Hendrix, A.; Sefton-Nash, E.; Siegler, M.A.; Lucey, P.G.; Retherford, K.D.; Williams, J.-P.; Greenhagen, B.T.; Paige, D.A. Evidence for exposed water ice in the Moon's south polar regions from Lunar Reconnaissance Orbiter ultraviolet albedo and temperature measurements. Icarus 2015, 255, 58-69. [CrossRef]

99. Li, S.; Lucey, P.G.; Milliken, R.E.; Hayne, P.O.; Fisher, E.; Williams, J.; Hurley, D.M.; Elphic, R.C. Direct evidence of surface exposed water ice in the lunar polar regions. Proc. Natl. Acad. Sci. USA 2018, 115, 8907-8912. [CrossRef] [PubMed]

100. Amitabh, S.; Suresh, K.; Srinivasan, T.P. Potential Landing Sites for Chandrayaan-2 Lander in Southern Hemisphere of Moon. In Proceedings of the 49th Lunar and Planetary Science Conference, Woodlands, TX, USA, 19-23 March 2018; Abstract \#1975.

101. Rivkin, A.S.; Howell, E.S.; Emery, J.P.; Sunshine, J. Evidence for $\mathrm{OH}$ or $\mathrm{H}_{2} \mathrm{O}$ on the surface of 433 Eros and 1036 Ganymed. Icarus 2018, 304, 74-82. [CrossRef]

102. De Sanctis, M.C.; Combe, J.-P.; Ammannito, E.; Palomba, E.; Longobardo, A.; McCord, T.B.; Marchi, S.; Capaccioni, F.; Capria, M.T.; Mittlefehldt, D.W.; et al. Detection of widespread hydrated materials on Vesta by the VIR imaging spectrometer onboard the Dawn mission. Astrophys. J. Lett. 2012, 758, L36. [CrossRef] 
103. Siegler, M.A.; Miller, R.S.; Keane, J.T.; Laneuville, M.; Paige, D.A.; Matsuyama, I.; Lawrence, D.J.; Crotts, A.; Poston, M.J. Lunar true polar wander inferred from polar hydrogen. Nature 2016, 531, 480-484. [CrossRef] [PubMed]

104. Needham, D.H.; Kring, D.A. Lunar volcanism produced a transient atmosphere around the ancient Moon. Earth Planet. Sci. Lett. 2017, 478, 175-178. [CrossRef]

105. Elkins-Tanton, L.T.; Parmentier, E.M.; Hess, P.C. Magma ocean fractional crystallization and cumulate overturn in terrestrial planets: Implications for Mars. Meteor. Planet. Sci. 2003, 38, 1753-1771. [CrossRef]

106. Elkins-Tanton, L. Magma Oceans in the Inner Solar System. Annu. Rev. Earth Planet. Sci. 2012, 40, 113-139. [CrossRef]

107. Shirley, D.N. A partially molten magma ocean model. In Proceedings of the Thirteenth Lunar and Planetary Science Conference, Houston, TX, USA, 15-19 March 1982; pp. A519-A527.

108. Longhi, J.; Ashwal, L.D. Two-stage models for lunar and terrestrial anorthosites: Petrogenesis without a magma ocean. In Proceedings of the Fifteenth Lunar and Planetary Science Conference, Houston, TX, USA, 12-16 March 1984; pp. C571-C584.

109. Ohtake, M.; Matsunaga, T.; Haruyama, J.; Yokota, Y.; Morota, T.; Honda, C.; Ogawa, Y.; Torii, M.; Miyamoto, H.; Arai, T.; et al. The global distribution of pure anorthosite on the Moon. Nature 2009, 461, 236-240. [CrossRef] [PubMed]

110. Donaldson Hanna, K.L.; Cheek, L.C.; Pieters, C.M.; Mustard, J.F.; Greenhagen, B.T.; Thomas, I.R.; Bowles, N.E. Global assessment of pure crystalline plagioclase across the Moon and implications for the evolution of the primary crust. J. Geophys. Res. Planets 2014, 119, 1516-1545. [CrossRef]

111. Conel, J.E.; Nash, D.B. Spectral reflectance and albedo of Apollo 11 lunar samples: Effects of irradiation and vitrification and comparison with telescopic observations. In Proceedings of the Apollo 11 Lunar Science Conference, Houston, TX, USA, 5-8 January 1970; Volume 3, pp. 2013-2024.

112. Bell, P.M.; Mao, H.K. Optical and chemical analysis of iron in Luna 20 plagioclase. Geochim. Cosmochim. Acta 1973, 37, 755-758. [CrossRef]

113. Adams, J.B.; Goullaud, L.H. Plagioclase feldspars: Visible and near infrared diffuse reflectance spectra as applied to remote sensing. In Proceedings of the 9th Lunar and Planetary Science Conference, Houston, TX, USA, 13-17 March 1978; pp. 2901-2909.

114. Piskorz, D.; Stevenson, D.J. The formation of pure anorthosite on the Moon. Icarus 2014, 239, $238-243$. [CrossRef]

115. Nagaoka, H.; Takeda, H.; Karouji, Y.; Ohtake, M.; Yamaguchi, A.; Yoneda, S.; Hasebe, N. Implications for the origins of pure anorthosites found in the feldspathic lunar meteorites, Dhofar 489 group. Earth Planets Space 2014, 66, 115. [CrossRef]

116. Dygert, N.; Lin, J.-F.; Marshall, E.W.; Kono, Y.; Gardner, J.E. A low viscosity lunar magma ocean forms a stratified anorthitic flotation crust with mafic poor and rich units. Geophys. Res. Lett. 2017, 44. [CrossRef]

117. Yamamoto, S.; Nakamura, R.; Matsunaga, T.; Ogawa, Y.; Ishihara, Y.; Morota, T.; Hirata, N.; Ohtake, M.; Hiroi, T.; Yokota, Y.; et al. Massive layer of pure anorthosite on the Moon. Geophys. Res. Lett. 2012, 39, L13201. [CrossRef]

118. Ohtake, M.; Takeda, H.; Matsunaga, T.; Yokota, Y.; Haruyama, J.; Morota, T.; Yamamoto, S.; Ogawa, Y.; Hiroi, T.; Karouji, Y.; et al. Asymmetric crustal growth on the Moon indicated by primitive farside high materials. Nat. Geosci. 2012, 5, 384-388. [CrossRef]

119. Cheek, L.C.; Hanna, K.L.D.; Pieters, C.M.; Head, J.W.; Whitten, J.L. The distribution and purity of anorthosite across the Orientale Basin: New perspectives from Moon Mineralogy Mapper Data. J. Geophys. Res. Planets 2013, 118, 1805-1820. [CrossRef]

120. Adams, J.B.; Horz, F.; Gibbon, R.V. Effects of shock-loading on the reflectance spectra of plagioclase, pyroxene, and glass. In Proceedings of the Lunar and Planetary Science X Conference, Houston, TX, USA, 19-23 March 1979; pp. 1-3.

121. Johnson, J.R.; Horz, F. Visible/near-infrared spectra of experimentally shocked plagioclase feldspars. J. Geophys. Res. 2003, 108, 5120. [CrossRef]

122. Yamamoto, S.; Nakamura, R.; Matsunaga, T.; Ogawa, Y.; Ishihara, Y.; Morota, T.; Hirata, N.; Ohtake, M.; Hiroi, T.; Yokota, Y.; et al. Featureless spectra on the Moon as evidence of residual lunar primordial crust. J. Geophys. Res. Planets 2015, 120, 2190-2205. [CrossRef] 
123. Pieters, C.M.; Hiroi, T.; Milliken, R.; Cheek, L. Abundance and distribution of lunar primary crust anorthosite: The featureless plagioclase challenge. In Proceedings of the 49th Lunar and Planetary Science Conference (LPSC), Woodlands, TX, USA, 19-23 March 2018; Abstract \#1698.

124. Borg, L.E.; Connelly, J.N.; Boyet, M.; Carlson, R.W. Chronological evidence that the Moon is either young or did not have a global magma ocean. Nature 2011, 477, 70-72. [CrossRef] [PubMed]

125. Borg, L.E.; Gaffney, A.M.; Shearer, C.K. A review of lunar chronology revealing a preponderance of 4.34-4.37 Ga ages. Meteor. Planet. Sci. 2015, 50, 715-732. [CrossRef]

126. Meyer, J.; Elkins-Tanton, L.T.; Wisdom, J. Coupled thermal-orbital evolution of the early Moon. Icarus 2010, 208, 1-10. [CrossRef]

127. Perera, V.; Jackson, A.P.; Elkins-Tanton, L.T.; Asphaug, E. Effect of reimpacting debris on the solidification of the lunar magma ocean. J. Geophys. Res. Planets 2018, 123, 1168-1191. [CrossRef]

128. Russell, S.S.; Joy, K.H.; Jeffries, T.E.; Consolmagno, G.J.; Kearsley, A. Heterogeneity in lunar anorthositemeteorites: Implications for the lunar magma ocean model. Philos. Trans. R. Soc. A 2014, 372, 20130241. [CrossRef] [PubMed]

129. Lawrence, D.J.; Feldman, W.C.; Barraclough, B.L.; Binder, A.B.; Elphic, R.C.; Maurice, S.; Miller, M.C.; Prettyman, T.H. High resolution measurements of absolute thorium abundance on the lunar surface. Geophys. Res. Lett. 1999, 26, 2681-2683. [CrossRef]

130. Lawrence, D.J.; Feldman, W.C.; Barraclough, B.L.; Binder, A.B.; Elphic, R.C.; Maurice, S.; Miller, M.C.; Prettyman, T.H. Thorium abundances on the lunar surface. J. Geophys. Res. 2000, 105, 20307-20331. [CrossRef]

131. Yamashita, N.; Hasebe, N.; Reedy, R.C.; Kobayashi, S.; Karouji, Y.; Hareyama, M.; Shibamura, E.; Kobayashi, M.-N.; Okudaira, O.; d’Uston, C.; et al. Uranium on the Moon: Global distribution and U/Th ratio. Geophys. Res. Lett. 2010, 37, L10201. [CrossRef]

132. Zhu, M.-H.; Chang, J.; Ma, T.; Ip, W.-H.; Fa, W.; Wu, J.; Cai, M.; Gong, Y.; Hu, Y.; Xu, A.; et al. Potassium Map from Chang'E-2 Constraints the Impact of Crisium and Orientale Basin on the Moon. Sci. Rep. 2013, 3, 1611. [CrossRef] [PubMed]

133. Wilson, J.T.; Lawrence, D.J.; Peplowski, P.N.; Eke, V.R.; Massey, R.J.; Teodoro, L.F.A. Improved resolution lunar prospector neutron and gamma ray data. In Proceedings of the 49th Lunar and Planetary Science Conference (LPSC), Woodlands, TX, USA, 19-23 March 2018; Abstract \#2103.

134. Wilson, J.T.; Eke, V.R.; Massey, R.J.; Elphic, R.C.; Jolliff, B.L.; Lawrence, D.J.; Llewellin, E.W.; McElwaine, J.N.; Teodoro, L.F.A. Evidence for explosive silicic volcanism on the Moon from the extended distribution of thorium near the Compton-Belkovich Volcanic Complex. J. Geophys. Res. Planets 2015, 120, 92-108. [CrossRef]

135. Chauhan, M.; Bhattacharya, S.; Saran, S.; Chauhan, P.; Dagar, A. Compton-Belkovich Volcanic Complex (CBVC): An ash flow caldera on the Moon. Icarus 2015, 253, 115-129. [CrossRef]

136. Glotch, T.; Lucey, P.; Bandfield, J.; Greenhagen, B.; Thomas, I.; Elphic, R.; Bowles, N.; Wyatt, M.; Allen, C.; Hanna, K.; et al. Highly silicic compositions on the Moon. Science 2010, 329, 1510-1513. [CrossRef] [PubMed]

137. Glotch, T.D.; Hagerty, J.J.; Lucey, P.G.; Hawke, B.R.; Giguere, T.A.; Arnold, J.A.; Williams, J.-P.; Jolliff, B.L.; Paige, D.A. The Mairan domes: Silicic volcanic constructs on the Moon. Geophys. Res. Lett. 2011, 38, L21204. [CrossRef]

138. Whitaker, E.A. Lunar color boundaries and their relationship to topographic features: A preliminary survey. Moon 1972, 4, 348-355. [CrossRef]

139. Malin, M. Lunar red spots: Possible pre-mare materials. Earth Planet. Sci. Lett. 1974, 21, 331-341. [CrossRef]

140. Head, J.W.; McCord, T.B. Imbrian-age highland volcanism on the Moon: The Gruithuisen and Mairan domes. Science 1978, 199, 1433-1436. [CrossRef] [PubMed]

141. Wilson, L.; Head, J. Lunar Gruithuisen and Mairan domes: Rheology and mode of emplacement. J. Geophys. Res. 2003, 108, 5012. [CrossRef]

142. Jolliff, B.L.; Wiseman, S.A.; Lawrence, S.J.; Tran, T.N.; Robinson, M.S.; Sato, H.; Hawke, B.R.; Scholten, F.; Oberst, J.; Hiesinger, H.; et al. Non-mare silicic volcanism on the lunar farside at Compton-Belkovich. Nat. Geosci. 2011. [CrossRef]

143. Ashley, J.W.; Robinson, M.S.; Stopar, J.D.; Glotch, T.D.; Hawke, B.R.; van der Bogert, C.H.; Hiesinger, H.; Lawrence, S.J.; Jolliff, B.L.; Greenhagen, B.T.; et al. The Lassell massif-A silicic lunar volcano. Icarus 2016, 273, 248-261. [CrossRef] 
144. Braden, S.E.; Stopar, J.D.; Robinson, M.S.; Lawrence, S.J.; van der Bogert, C.H.; Hiesinger, H. Evidence for basaltic volcanism on the Moon within the past 100 million years. Nat. Geosci. 2014. [CrossRef]

145. El Baz, F.; Worden, A.W. In Apollo 15 Preliminary Science Report 25-1-25-25; NASA SP-289; US Government Printing Office: Washington, DC, USA, 1972.

146. Strain, P.; El-Baz, F. The geology and morphology of Ina. In Proceedings of the 11th Lunar and Planetary Science Conference, Houston, TX, USA, 17-21 March 1980; Volume 3, pp. 2437-2446.

147. Garry, W.; Robinson, M.; Zimbelman, J.; Bleacher, J.; Hawke, B.; Crumpler, L.; Braden, S.; Sato, H. The origin of Ina: Evidence for inflated lava flows on the Moon. J. Geophys. Res. 2012, 117. [CrossRef]

148. Wilson, L.; Head, J.W. Eruption of magmatic foams on the Moon: Formation in the waning stages of dike emplacement events as an explanation of "irregular mare patches". J. Volcanol. Geotherm. Res. 2017, 335, 113-127. [CrossRef]

149. Qiao, L.; Head, J.W.; Xiao, L.; Wilson, L.; Dufek, J.D. The role of substrate characteristics in producing anomalously young crater retention ages in volcanic deposits on the Moon: Morphology, topography, subresolution roughness, and mode of emplacement of the Sosigenes lunar irregular mare patch. Meteor. Planet. Sci. 2018, 53, 778-812. [CrossRef]

150. Elder, C.M.; Hayne, P.O.; Bandfield, J.L.; Ghent, R.R.; Williams, J.-P.; Donaldson Hanna, K.L.; Paige, D.A. Young lunar volcanic features: Thermophysical properties and formation. Icarus 2017, 290, $224-237$. [CrossRef]

151. Srivastava, N.; Kumar, D.; Gupta, R.P. Young viscous flows in the Lowell crater of Orientale basin, Moon: Impact melts or volcanic eruptions? Planet. Space Sci. 2013, 87, 37-45. [CrossRef]

152. Gupta, R.P.; Srivastava, N.; Tiwari, R.K. Evidences for relatively new volcanic flows on the Moon. Curr. Sci. 2014, 107, 454-460.

153. Plescia, J.B.; Spudis, P.D. Impact melt flows at Lowell crater. Planet. Space Sci. 2014, 103, 219-227. [CrossRef]

154. Srivastava, N.; Varatharajan, I. Geomorphology of Lowell crater region on the Moon. Icarus 2016, 266, 44-56. [CrossRef]

155. Chauhan, P.; Kaur, P.; Srivastava, N.; Bhattacharya, S.; Ajai; Kumar, A.S.K.; Goswami, J.N. Compositional and morphological analysis of high resolution remote sensing data over central peak of Tycho crater on the Moon: Implications for understanding lunar interior. Curr. Sci. 2012, 102, 1041-1046.

156. Ling, Z.; Jolliff, B.L.; Wang, A.; Li, C.; Liu, J.; Zhang, J.; Li, B.; Sun, L.; Chen, J.; Xiao, L.; et al. Correlated compositional and mineralogical investigations at the Chang'e-3 landing site. Nat. Commun. 2015, 6, 8880. [CrossRef] [PubMed]

157. Zhang, J.; Yang, W.; Hu, S.; Lin, Y.; Fang, G.; Li, C.; Peng, W.; Zhu, S.; He, Z.; Zhou, B.; et al. Volcanic history of the Imbrium basin: A close-up view from the lunar rover Yutu. Proc. Natl. Acad. Sci. USA 2015, 112, 5342-5347. [CrossRef] [PubMed]

158. Wöhler, C.; Grumpe, A.; Berezhnoy, A.; Bhatt, M.U.; Mall, U. Integrated topo- graphic, photometric and spectral analysis of the lunar surface: Application to impact melt flows and ponds. Icarus 2014, 235, 86-122. [CrossRef]

159. Lucey, P.G.; Lemelin, M.; Ohtake, M.; Gaddis, L.R.; Greenhagen, B.T.; Yamamoto, S.; Hare, T.M.; Taylor, J.; Martel, L.; Norman, J. Global High Resolution Mineral Maps of the Moon Using Data from the Kaguya Multiband Imager and LRO Diviner Lunar Radiometer. In Proceedings of the American Geophysical Union, Fall General Assembly 2016, San Francisco, CA, USA, 12-16 December 2016; abstract id.P53A-2169.

160. Sato, H.; Robinson, M.S.; Lawrence, S.J.; Denevi, B.W.; Hapke, B.; Jolliff, B.L.; Hiesinger, H. Lunar $\mathrm{mare}^{\mathrm{TiO}} 2$ abundances estimated from UV/Vis reflectance. Icarus 2017, 296, 216-238. [CrossRef]

161. Hapke, B.; Sato, H.; Robinson, M. Lunar Reconnaissance Orbiter Wide Angle Camera Algorithm for $\mathrm{TiO}_{2}$ Abundances on the Lunar Surface, including the Highlands and Low-Ti Maria. Icarus 2019. [CrossRef]

162. Whitten, J.; Head, J.W.; Staid, M.; Pieters, C.M.; Mustard, J.; Clark, R.; Nettles, J.; Klima, R.L.; Taylor, L. Lunar mare deposits associated with the Orientale impact basin: New insights into mineralogy, history, mode of emplacement, and relation to Orientale Basin evolution from Moon Mineralogy Mapper (M3) data from Chandrayaan-1. J. Geophys. Res. Planets 2011, 116, 1-33. [CrossRef]

163. Kramer, G.Y.; Jolliff, B.L.; Neal, C.R. Distinguishing high-alumina mare basalts using Clementine UVVIS and Lunar Prospector GRS data: Mare Moscoviense and Mare Nectaris. J. Geophys. Res. Planets 2008, 113, 1002. [CrossRef] 
164. Haruyama, J.; Ohtake, M.; Matsunaga, T.; Morota, T.; Honda, C.; Yokota, Y.; Abe, M.; Ogawa, Y.; Miyamoto, H.; Iwasaki, A.; et al. Long-lived volcanism on the lunar farside revealed by SELENE Terrain Camera. Science 2009, 323, 905-908. [CrossRef] [PubMed]

165. Bhatt, M.; Wohler, C.; Dhingra, D.; Thangjam, G.; Rommel, D.; Mall, U.; Bhardwaj, A.; Grumpe, A. Compositional studies of Mare Moscoviense: New perspectives from Chandrayaan-1 VIS-NIR data. Icarus 2018, 303, 149-165. [CrossRef]

166. Hackwill, T. Stratigraphy, evolution and volume of basalts in Mare Serenitatis. Meteor. Planet. Sci. 2010, 45, 210-219. [CrossRef]

167. Kaur, P.; Bhattacharya, S.; Chauhan, P.; Ajai; Kumar, A.S.K. Mineralogy of Mare Serenitatis on the near side of the Moon based on Chandrayaan-1 Moon Mineralogy Mapper (M3) observations. Icarus 2013, 222, 137-148. [CrossRef]

168. Dhingra, D.; Giguere, T.; Mouginis-Mark, P.; Boyce, J. Basalt Mineralogy Variations at Tsiolkovskiy Crater: Insights into the Eruption History on the Lunar Far Side. In Proceedings of the Asia Oceania Geoscience Society (AOGS) Meeting, Honolulu, HI, USA, 3-8 June 2018; Abstract\# PS11-A017.

169. Varatharajan, I.; Srivastava, N.; Murty, S.V.S. Mineralogy of young lunar mare basalts: Assessment of temporal and spatial heterogeneity using M3 data from Chandrayaan-1. Icarus 2014, 236, 56-71. [CrossRef]

170. Prissel, T.C.; Parman, S.W.; Jackson, C.R.M.; Rutherford, M.J.; Hess, P.C.; Head, J.W.; Cheek, L.; Dhingra, D.; Pieters, C.M. Pink Moon: The petrogenesis of pink spinel anorthosites and implications concerning Mg-suite magmatism. Earth Planet. Sci. Lett. 2014, 403, 144-156. [CrossRef]

171. Prissel, T.C.; Whitten, J.L.; Parman, S.W.; Head, J.W. On the potential for lunar highlands Mg-suite extrusive volcanism and implications concerning crustal evolution. Icarus 2016, 277, 319-329. [CrossRef]

172. Gaddis, L.R.; Pieters, C.M.; Hawke, B.R. Remote sensing of lunar pyroclastic mantling deposits. Icarus 1985, 61, 461-489. [CrossRef]

173. Gaddis, L.R.; Staid, M.I.; Tyburczy, J.A.; Hawke, B.R.; Petro, N.E. Compositional analyses of lunar pyroclastic deposits. Icarus 2003, 161, 262-280. [CrossRef]

174. Sunshine, J.M.; Besse, S.; Petro, N.E.; Pieters, C.M.; Head, J.W.; Taylor, L.A.; Klima, R.L.; Isaacson, P.J.; Boardman, J.W.; Clark, R.C.; et al. Hidden in plain sight: Spinel-rich deposits on the nearside of theMoon as revealed by Moon Mineralogy Mapper (M3). In Proceedings of the 41st Lunar and Planetary Science Conference, Woodlands, TX, USA, 1-5 March 2010; Abstract 1508.

175. Yamamoto, S.; Nakamura, R.; Matsunaga, T.; Ogawa, Y.; Ishihara, Y.; Morota, T.; Hirata, N.; Ohtake, M.; Hiroi, T.; Yokota, Y.; et al. A new type of pyroclastic deposit on the Moon containing Fe-spinel and chromite. Geophys. Res. Lett. 2015, 40, 4549-4554. [CrossRef]

176. Gaddis, L.R.; Hawke, B.R.; Robinson, M.S.; Coombs, C.R. Compositional analyses of small lunar pyroclastic deposits using clementine multispectral data. J. Geophys. Res. 2000, 105, 4245-4262. [CrossRef]

177. Trang, D.; Gillis-Davis, J.J.; Lemelin, M.; Cahill, J.T.S.; Hawke, B.R.; Giguere, T.A. The compositional and physical properties of localized lunar pyroclastic deposits. Icarus 2017, 283, 232-253. [CrossRef]

178. Hirschmann, M.M. Fe-carbonyl is a key player in planetary magmas. Proc. Natl. Acad. Sci. USA 2013, 110, 7967-7968. [CrossRef] [PubMed]

179. Wetzel, D.T.; Rutherford, M.J.; Jacobsen, S.D.; Hauri, E.H.; Saal, A.E. Degassing of reduced carbon from planetary basalts. Proc. Natl. Acad. Sci. USA 2013, 110, 8010-8013. [CrossRef] [PubMed]

180. Haruyama, J.; Hioki, K.; Shirao, M.; Morota, T.; Hiesinger, H.; van der Bogert, C.H.; Miyamoto, H.; Iwasaki, A.; Yokota, Y.; Ohtake, M.; et al. Possible lunar lava tube skylight observed by SELENE cameras. Geophys. Res. Lett. 2009, 36, L21206. [CrossRef]

181. Robinson, M.S.; Ashley, J.W.; Boyd, A.K.; Wagner, R.V.; Speyerer, E.J.; Hawke, B.R.; Hiesinger, H.; van der Bogert, C.H. Confirmation of sublunarean voids and thin layering in mare deposits. Planet. Space Sci. 2012, 69, 18-27. [CrossRef]

182. Kaku, T.; Haruyama, J.; Miyake, W.; Kumamoto, A.; Ishiyama, K.; Nishibori, T.; Yamamoto, K.; Crites, S.T.; Michikami, T.; Yokota, Y.; et al. Detection of intact lava tubes at Marius Hills on the Moon by SELENE (Kaguya) lunar radar sounder. Geophys. Res. Lett. 2017, 44, 10155-10161. [CrossRef]

183. Haruyama, J.; Morota, T.; Kobayashi, S.; Sawai, S.; Lucey, P.G.; Shirao, M.; Nishino, M.N. Lunar Holes and Lava Tubes as Resources for Lunar Science and Exploration. In Moon; Badescu, V., Ed.; Springer: Berlin/Heidelberg, Germany, 2012. 
184. Wagner, R.V.; Robinson, M.S. Distribution, Formation Mechanisms, and Significance of Lunar Pits. Icarus 2014, 237, 52-60. [CrossRef]

185. Robinson, M.S.; Thanga, J.; Wagner, R.V.; Hernandez, V.A. ARNE-Sublunarean Explorer. In Proceedings of the Annual Meeting of the Lunar Exploration Analysis Group, Laurel, MD, USA, 22-24 October 2014; Abstract\# 3025.

186. Hong, I.-S.; Yi, Y.; Yu, J.; Haruyama, J. 3D Modeling of Lacus Mortis Pit Crater with Presumed Interior Tube Structure. J. Astron. Space Sci. 2015, 32, 113-120. [CrossRef]

187. Blair, D.M.; Chappaz, L.; Sood, R.; Milbury, C.; Bobet, A.; Melosh, H.J.; Howell, K.C.; Freed, A.M. The structural stability of lunar lava tubes. Icarus 2017, 282, 47-55. [CrossRef]

188. Kerber, L.; Nesnas, I.; Keszthelyi, L.; Head, J.W.; Denevi, B.; Hayne, P.O.; Mitchell, K.; Ashley, J.W.; Whitten, J.L.; Stickle, A.M.; et al. Moon Diver: A Discovery Mission Concept for understanding the history of the mare basalts through the exploration of a lunar mare pit. In Proceedings of the 49th LPSC, Fukushima, Japan, 18-20 April 2018; Abstract \#1956.

189. Dorrington, G.E. Rationale and concept for a lunar pit reconnaissance probe. Aeronaut. J. 2018, 122, 666-691. [CrossRef]

190. Xiao, L.; Zhu, P.; Fang, G.; Xiao, Z.; Zou, Y.; Zhao, J.; Zhao, N.A.; Yuan, Y.; Qiao, L.E.; Zhang, X.; et al. A young multilayered terrane of the northern Mare Imbrium revealed by Chang'E-3 mission. Science 2015, 347, 1226-1229. [CrossRef] [PubMed]

191. Andrews-Hanna, J.C.; Asmar, S.W.; Head, J.W.; Kiefer, W.S.; Konopliv, A.S.; Lemoine, F.G.; Matsuyama, I.; Mazarico, E.; McGovern, P.J.; Melosh, H.J.; et al. Ancient igneous intrusions and early expansion of the Moon revealed by GRAIL gravity gradiometry. Science 2013, 339, 675-678. [CrossRef] [PubMed]

192. Schultz, P. Floor-fractured lunar craters. Moon 1976, 15, 241-273. [CrossRef]

193. Pieters, C.M. Bullialdus-Strengthening the case for lunar plutons. Geophys. Res. Lett. 1991, 18, $2129-2132$. [CrossRef]

194. Cadogan, P.H. Oldest and largest lunar basin? Nature 1974, 250, 315-316. [CrossRef]

195. Whitaker, E.A. The lunar Procellarum basin. In Multi-Ring Basins: Formation and Evolution; Pergamon Press: New York, NY, USA; Oxford, UK, 1981; Volume 12A, pp. 105-111.

196. Andrews-Hanna, J.C.; Besserer, J.; Head, J.W., III; Howett, C.J.A.; Kiefer, W.S.; Lucey, P.J.; McGovern, P.J.; Melosh, H.J.; Neumann, G.A.; Phillips, R.J.; et al. Structure and evolution of the lunar Procellarum region as revealed by GRAIL gravity data. Nature 2014, 514, 68-71. [CrossRef] [PubMed]

197. Andrews-Hanna, J.C.; Zuber, M.T. Elliptical craters and basins on the terrestrial planets. In Large Meteorite Impacts and Planetary Evolution IV; Gibson, R.L., Reimold, W.U., Eds.; Special Paper 465; Geological Society of America: Boulder, CO, USA, 2010; pp. 1-13.

198. Hall, J.L.; Solomon, S.C.; Head, J.W. Lunar floor-fractured craters: Evidence of viscous relaxation of crater topography. J. Geophys. Res. 1981, 86, 9537-9552. [CrossRef]

199. Jozwiak, L.M.; Head, J.W.; Zuber, M.T.; Smith, D.E.; Neumann, G.A. Lunar floor-fractured craters: Classification, distribution, origin and implications for magmatism and shallow crustal structure. J. Geophys. Res. 2012, 117, E11005. [CrossRef]

200. Jozwiak, L.M.; Head, J.W.; Wilson, L. Lunar floor-fractured craters as magmatic intrusions: Geometry, modes of emplacement, associated tectonic and volcanic features, and implications for gravity anomalies. Icarus 2015, 248, 424-447. [CrossRef]

201. Jozwiak, L.M.; Head, J.W., III; Neumann, G.A.; Wilson, L. Observational constraints on the identification of shallow lunar magmatism: Insights from floor-fractured craters. Icarus 2017, 283, 224-231. [CrossRef]

202. Pieters, C.M.; Besse, S.; Boardman, J.; Buratti, B.; Cheek, L.; Clark, R.N.; Combe, J.P.; Dhingra, D.; Goswami, J.N.; Green, R.O.; et al. Mg-spinel lithology: A new rock type on the lunar farside. J. Geophys. Res. Planet 2011, 116, E00G08. [CrossRef]

203. Dhingra, D.; Pieters, C.M.; Boardman, J.W.; Head, J.W.; Isaccson, P.J.; Taylor, L.A. Compositional diversity at Theophilus crater: Understanding the geological context of Mg-Spinel bearing central peaks. Geophys. Res. Lett. 2011, 38, L11201. [CrossRef]

204. Pieters, C.M.; Hanna, K.D.; Cheek, L.; Dhingra, D.; Prissel, T.; Jackson, C.; Moriarty, D.; Parman, S.; Taylor, L.A. The distribution of Mg-spinel across the Moon and constraints on crustal origin. Am. Miner. 2014, 99, 1893-1910. [CrossRef] 
205. Treiman, A.H.; Gross, J.; Glazner, A.F. Lunar rocks rich in Mg-Al Spinel: Enthalpy constraints suggest origins by impact melting. In Proceedings of the 46th Lunar and Planetary Science Conference (LPSC), Woodlands, TX, USA, 16-20 March 2015; Abstract \#2518.

206. Treiman, A.H.; Gross, J.; Kulis, M.J.; Glazner, A.F. Lunar Spinel Anorthosites: Updated Constraints from Enthalpy. In Proceedings of the 80th Annual Meeting of the Meteoritical Society, Santa Fe, NM, USA, 23-28 July 2017; Abstract \#6226.

207. Kaur, P.; Chauhan, P.; Ajai. Exposures of Mg-Spinel on an evolved silicic lithology Hansteen Alpha on the Moon. In Proceedings of the 44th Lunar and Planetary Science Conference (LPSC), Woodlands, TX, USA, 18-22 March 2013; Abstract \#1348.

208. Boyce, J.M.; Giguere, T.A.; Hawke, B.R.; Mouginis-Mark, P.J.; Robinson, M.S.; Lawrence, S.J.; Trang, D.; Clegg-Watkins, R.N. Hansteen Mons: An LROC geological perspective. Icarus 2017, 283, 254-267. [CrossRef]

209. Dhingra, D.; Glotch, T.D.; Prissel, T.C.; Parman, S.W.; Pieters, C.M.; Greenhagen, B.T. Mg-Spinel Exposures within Silica-rich setting on Hansteen Alpha: Probing the Gologic Context. In Proceedings of the 48th Lunar and Planetary Science Conference (LPSC), Woodlands, TX, USA, 20-24 March 2017; Abstract \#2104.

210. Yamamoto, S.; Nakamura, R.; Matsunaga, T.; Ogawa, Y.; Ishihara, Y.; Morota, T.; Hirata, N.; Ohtake, M.; Hiroi, T.; Yokota, Y.; et al. Possible mantle origin of olivine around lunar impact basins detected by SELENE. Nat. Geosci. 2010, 3, 533-536. [CrossRef]

211. Corley, L.M.; McGovern, P.J.; Kramer, G.Y.; Lemelin, M.; Trang, D.; Gillis-Davis, J.J.; Taylor, G.J.; Powell, K.E.; Kiefer, W.S.; Wieczorek, M.; et al. Olivine-bearing lithologies on the Moon: Constraints on origins and transport mechanisms from M3 spectroscopy, radiative transfer modeling, and GRAIL crustal thickness. Icarus 2018, 300, 287-304. [CrossRef]

212. Arnold, J.A.; Glotch, T.D.; Lucey, P.G.; Song, E.; Thomas, I.R.; Bowles, N.E.; Greenhagen, B.T. Constraints on olivine-rich rock types on the Moon as observed by Diviner and M3: Implications for the formation of the lunar crust. J. Geophys. Res. Planets 2016, 121, 1342-1361. [CrossRef]

213. Miljković, K.; Wieczorek, M.A.; Collins, G.S.; Solomon, S.C.; Smith, D.E.; Zuber, M.T. Excavation of the lunar mantle by basin-forming impact events on the Moon. Earth Planet. Sci. Lett. 2015, 409, 243-251. [CrossRef]

214. Klima, R.L.; Pieters, C.M.; Boardman, J.W.; Green, R.O.; Head, J.W., III; Isaacson, P.J.; Mustard, J.F.; Nettles, J.W.; Petro, N.E.; Staid, M.I.; et al. New insights into lunar petrology: Distribution and composition of prominent low-Ca pyroxene exposures as observed by the Moon Mineralogy Mapper (M3). J. Geophys. Res. 2011, 116, E00G06. [CrossRef]

215. Ogawa, Y.; Matsunaga, T.; Nakamura, R.; Saiki, K.; Ohtake, M.; Hiroi, T.; Takeda, H.; Arai, T.; Yokota, Y.; Yamamoto, S.; et al. The widespread occurrence of high-calcium pyroxene in bright-ray craters on the Moon and implications for lunar-crust composition. Geophys. Res. Lett. 2011, 38, L17202. [CrossRef]

216. Cintala, M.J.; Grieve, R.A.F. Scaling impact melting and crater dimensions: Implications for the lunar cratering record. Meteor. Planet. Sci. 1998, 33, 889-912. [CrossRef]

217. Bray, V.J.; Tornabene, L.L.; Keszthelyi, L.P.; McEwen, A.S.; Hawke, B.R.; Giguere, T.A.; Kattenhorn, S.A.; Garry, W.B.; Rizk, B.; Caudill, C.M.; et al. New insight into lunar impact melt mobility from LRO camera. Geophys. Res. Lett. 2010, 37, L21202. [CrossRef]

218. Carter, L.M.; Neish, C.D.; Bussey, D.B.J.; Spudis, P.D.; Patterson, G.W.; Cahill, J.T.; Raney, R.K. Initial observations of lunar impact melts and ejecta flows with the Mini-RF radar. J. Geophys. Res. 2012, 117, E00H09. [CrossRef]

219. Neish, C.D.; Madden, J.; Carter, L.M.; Hawke, B.R.; Giguere, T.; Bray, V.J.; Osinski, G.R.; Cahill, J.T.S. Global distribution of lunar impact melt flows. Icarus 2014, 239, 105-117. [CrossRef]

220. Stopar, J.D.; Hawke, B.R.; Robinson, M.S.; Denevi, B.W.; Giguere, T.A.; Koeber, S.D. Occurrence and mechanisms of impact melt emplacement at small lunar Craters. Icarus 2014, 243, 337-357. [CrossRef]

221. Robinson, M.S.; Thomas, P.C.; Plescia, J.B.; Denevi, B.W.; Burns, K.N.; Bowman-Cisneros, E.; Henriksen, M.R.; van der Bogert, C.H.; Hiesinger, H.; Mahanti, P.; et al. An exceptional grouping of lunar highland smooth plains: Geography, morphology, and possible origins. Icarus 2016. [CrossRef]

222. Dhingra, D.; Head, J.W.; Pieters, C.M. Geological mapping of impact melt deposits at lunar complex craters Jackson and Tycho: Morphologic and topographic diversity and relation to the cratering process. Icarus 2017, 283, 268-281. [CrossRef]

223. Smrekar, S.; Pieters, C.M. Near-infrared spectroscopy of probable impact melt from three large lunar highland craters. Icarus 1985, 63, 442-452. [CrossRef] 
224. Tompkins, S.; Pieters, C.M. Spectral characteristics of lunar impact melt and inferred mineralogy. Meteor. Planet. Sci. 2010, 45, 1152-1169. [CrossRef]

225. Dhingra, D.; Pieters, C. Mineralogical diversity of impact melts on central peak of Tycho and its vicinity. In Proceedings of the Annual Meeting of the Lunar Exploration Analysis Group, Houston, TX, USA, 7-9 November 2011; LPI Contribution No. 1646. p. 11.

226. Dhingra, D.; Pieters, C.M.; Head, J.W.; Isaacson, P.J. Large mineralogically distinct impact melt feature at Copernicus crater-Evidence for retention of compositional heterogeneity. Geophys. Res. Lett. 2013, 40, 1043-1048. [CrossRef]

227. Dhingra, D. Integrated Mineralogy and High Resolution Geologic Context of Lunar Impact Melt Deposits: Implications for Crustal Diversity and the Impact Cratering Process. Ph.D. Thesis, Brown University, Providence, RI, USA, 2015.

228. Dhingra, D.; Pieters, C.M. Impact melt cover on central peaks of impact craters: Implications for deriving crustal compositions. In Proceedings of the New Views of the Moon 2 Europe, Münster, Germany, 4-5 May 2017; Abstract \#6004.

229. Dhingra, D.; Pieters, C.M.; Head, J.W. Multiple origins for olivine at Copernicus crater. Earth Planet. Sci. Lett. 2015, 420, 95-101. [CrossRef]

230. Warren, P.H.; Claeys, P.; Cedillo-Pardo, E. Mega-impact melt petrology (Chicxulub, Sudbury, and the Moon): Effects of scale and other factors on potential for fractional crystallization and development of cumulates. In The Cretaceous-Tertiary Event and Other Catastrophes in Earth History; Ryder, G., Fastovsky, D.E., Gartner, S., Eds.; Geological Society America: Boulder, CO, USA, 1996; Volume 307, pp. 105-124.

231. Neal, C.R.; Donohue, P.H.; Fagan, A.; Hui, H.; O'Sullivan, K. Using quantitative petrography to distinguish between pristine basalts and impact melts from the Moon. In Proceedings of the 42nd Lunar and Planetary Science Conference, Woodlands, TX, USA, 7-11 March 2011; Abstract \#2668.

232. Neal, C.R.; Donohue, P.; Fagan, A.L.; O'Sullivan, K.; Oshrin, J.; Roberts, S. Distinguishing between basalts produced by endogenic volcanism and impact processes: A non-destrwuctive method using quantitative petrography of lunar basaltic samples. Geochim. Cosmochim. Acta 2015, 148, 62-80. [CrossRef]

233. Vaughan, W.M.; Head, J.W.; Wilson, L.; Hess, P.C. Geology and petrology of enormous volumes of impact melt on the Moon: A case study of the Orientale basin impact melt sea. Icarus 2013, 223, 749-765. [CrossRef]

234. Hurwitz, D.M.; Kring, D.A. Differentiation of the South Pole-Aitken basin impact melt sheet: Implications for lunar exploration. J. Geophys. Res. 2014, 119, 1110-1133. [CrossRef]

235. Spudis, P.D.; Martin, D.J.P.; Kramer, G. Geology and composition of the Orientale Basin impact melt sheet. J. Geophys. Res. Planets 2014, 119, 19-29. [CrossRef]

236. Moriarty, D.P., III; Pieters, C.M. The character of South Pole-Aitken Basin: Patterns of surface and subsurface composition. J. Geophys. Res. Planets 2018, 123. [CrossRef]

237. Ohtake, M.; Uemoto, K.; Yokota, Y.; Morota, T.; Yamamoto, S.; Nakamura, R.; Haruyama, J.; Iwata, T.; Matsunaga, T.; Ishihara, Y. Geologic structure generated by large-impact basin formation observed at the South Pole-Aitken Basin on the Moon. Geophys. Res. Lett. 2014, 41, 2738-2745. [CrossRef]

238. Pieters, C.M.; Head, J.W.; Gaddis, L.; Jolliff, B.; Duke, M. Rock types of South Pole-Aitken Basin and extent of basaltic volcanism. J. Geophys. Res. 2001, 106, 28001-28022. [CrossRef]

239. Moriarty, D.P., III; Pieters, C.M. The nature and origin of Mafic Mound in the South Pole-Aitken Basin. Geophys. Res. Lett. 2015, 42. [CrossRef]

240. Melosh, H.J.; Kendall, J.; Horgan, B.; Johnson, B.C.; Bowling, T.; Lucey, P.G.; Taylor, G.J. South Pole-Aitken basin ejecta reveal the Moon's upper mantle. Geology 2017, 45, 1063-1066. [CrossRef]

241. Cohen, B.A.; Hayne, P.O.; Greenhagen, B.T.; Paige, D.A. Lunar Flashlight: Exploration and science at the moon with a $6 \mathrm{U}$ CubeSat. In Proceedings of the Annual Meeting of the Lunar Exploration Analysis Group, Columbia, MD, USA, 20-22 October 2015; Abstract \#2008.

242. Zhao, J.; Xiao, L.; Qiao, L.; Glotch, T.D.; Huang, Q. The Mons Rümker volcanic complex of the Moon: A candidate landing site for the Chang'E-5 mission. J. Geophys. Res. Planets 2017, 122, 1419-1442. [CrossRef]

243. Huang, J.; Xiao, Z.; Flahaut, J.; Martinot, M.; Head, J.; Xiao, X.; Xie, M.; Xiao, L. Geological characteristics of Von Kármán crater, northwestern South Pole-Aitken Basin: Chang'E-4 landing site region. J. Geophys. Res. Planets 2018, 123, 1684-1700. [CrossRef] 
244. Garrick-Bethell, I.; Pieters, C.M.; Russell, C.T.; Weiss, B.P.; Halekas, J.; Larson, D.; Poppe, A.R.; Lawrence, D.J.; Elphic, R.C.; Hayne, P.O.; et al. Nanoswarm: A cubesat discovery mission to study space weathering, lunar magnetism, lunar water and small-scale magnetospheres. In Proceedings of the 46th Lunar and Planetary Science Conference (LPSC), Woodlands, TX, USA, 16-20 March 2015; Abstract \#3000.

245. Ivanov, M.A.; Hiesinger, H.; Abdrakhimov, A.M.; Basilevsky, A.T.; Head, J.W.; Pasckert, J.-H.; Bauch, K.; van der Bogert, C.H.; Gläser, P.; Kohanov, A. Landing site selection for Luna-Glob mission in crater Boguslawsky. Planet. Space Sci. 2015, 117, 45-63. [CrossRef]

246. Mathew, J.; Prakash, A.; Sarpotdar, M.; Sreejith, A.G.; Safonova, M.; Murthy, J. An ultraviolet imager to study bright UV sources. In Proceedings of the SPIE Space Telescopes and Instrumentation 2016: Ultraviolet to Gamma Ray, Edinburgh, UK, 18 July 2016; Volume 9905, p. 990532. [CrossRef]

247. Zacny, K.; Paulsen, G.; Chu, P.; Craft, J.; Mueller, R.; Thornton, J. Lunar Prospecting Rover Utilizing a Lunar Drill, Pneumatic Excavator, and Gas Jet Trencher. In Proceedings of the AIAA SPACE 2012 Conference \& Exposition, AIAA SPACE Forum, Pasadena, CA, USA, 11-13 September 2012. [CrossRef]

248. Spudis, P.; Richards, R.; Burns, J.O. Moon Express: Lander Capabilities and Initial Payload and Mission. In Proceedings of the American Geophysical Union, Fall Meeting 2013, San Francisco, CA, USA, 9-13 December 2013; abstract id.P53F-09.

249. Huber, S.A.; Hendrickson, D.B.; Jones, H.L.; Thornton, J.P.; Whittaker, W.L.; Wong, U.Y. Astrobotic Technology: Planetary Pits and Caves for Science and Exploration. In Proceedings of the Annual Meeting of the Lunar Exploration Analysis Group, Laurel, MD, USA, 22-24 October 2014; LPI Contribution No. 1820, id.3065.

250. Kaushal, P.; Wani, S. Thermal Design \& Analysis of Space-Craft for Lunar Descent and Operations; SAE Technical Paper 2016-01-0212; SAE 2016 World Congress and Exhibition: Detroit, MI, USA, 2016.

251. Spudis, P.D.; Richards, R.D. The Robotic Architecture of Moon Express: Exploration, Resources, and Delivery. In Proceedings of the 2017 Annual Meeting of the Lunar Exploration Analysis Group, Columbia, MD, USA, 10-12 October 2017; LPI Contribution No. 2041, id.5035.

252. Menon, M.S.; Kothandhapani, A.; Sundaram, N.S.; Nagaraj, S.; Raghavan, V. Terrain-based Analysis as a Design and Planning Tool for Operations of a Lunar Exploration Rover for the Team Indus Lunar Mission. In Proceedings of the SpaceOps Conference, Marseille, France, 28 May-1 June 2018. [CrossRef]

253. Schrunk, D.; Sharpe, B.; Cooper, B.L.; Thangavelu, M. The Moon, Resources, Future Development and Settlement; Praxis Publishing: Chichester, UK, 2008; 261p, ISBN 978-0-387-36055-3.

254. Captain, J.; Elphic, R.; Colaprete, A.; Zacny, K.; Paz, A. Resource Prospector Instrumentation for Lunar Volatiles Prospecting, Sample Acquisition, and Processing. In Proceedings of the Earth and Space 2016: Engineering for Extreme Environments, Orlando, FL, USA, 1-15 April 2016. [CrossRef]

255. Van Susante, P.J.; Metzger, P.T. Design, Test, and Simulation of Lunar and Mars Landing Pad Soil Stabilization Built with In Situ Rock Utilization. In Proceedings of the Earth and Space 2016: Engineering for Extreme Environments, Orlando, FL, USA, 1-15 April 2016. [CrossRef]

256. Colaprete, A.; Elphic, R.; Andrews, D.; Trimble, J.; Bluethmann, B.; Quinn, J.; Chavers, G. Resource prospector: An update on the lunar volatiles prospecting and ISRU demonstration mission. In Proceedings of the 48th Lunar and Planetary Science Conference (LPSC), Woodlands, TX, USA, 20-24 March 2017; Abstract \#1685.

(C) 2018 by the author. Licensee MDPI, Basel, Switzerland. This article is an open access article distributed under the terms and conditions of the Creative Commons Attribution (CC BY) license (http://creativecommons.org/licenses/by/4.0/). 